ERK2 IS REQUIRED FOR EFFICIENT TERMINAL DIFFERENTIATION OF SKELETAL MYOBLASTS

By

JU LI

A THESIS PRESENTED TO THE GRADUATE SCHOOL OF THE UNIVERSITY OF FLORIDA IN PARTIAL FULFILLMENT OF THE REQUIREMENTS FOR THE DEGREE OF MASTER OF SCIENCE

UNIVERSITY OF FLORIDA

2007 
Copyright 2007

by

$\mathrm{Ju} \mathrm{Li}$ 


\section{ACKNOWLEDGMENTS}

Many great people provide their generous help to support me to complete this thesis. First of all, I would like to thank my advisor, Dr. Sally Johnson, who supported me all the way. Since I got the opportunity to study in her lab, her guidance, trust, and understanding helped me to complete my degree. I would also like to thank my committee members, Dr. Alan Ealy and Dr. Joel Yelich. I thank them for their time and assistance for my graduate program. Your advice help me complete my master's project and will be a great benefit for my future research.

I would specially thank all of my lab mates. Xu Wang has been helping me with my research since the very first day I enter the lab. She is my best teacher and friend. I also thank Dane Winner, Sarah Reed, Jenelle McQuown, Sara Ouellette, and Shige Tsuda. I could not complete my research without their help.

I thank my dear Mom and Dad who always believe that I am the best. Last but most importantly, I thank my husband $\mathrm{Bi}$, who support my work and go with me through all the hard times. 


\section{TABLE OF CONTENTS}

page

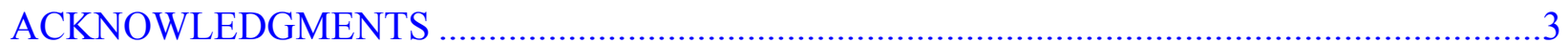

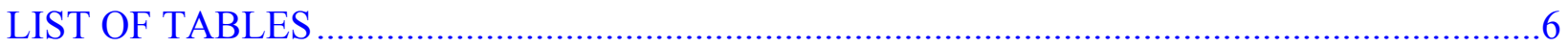



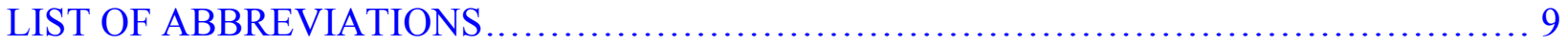

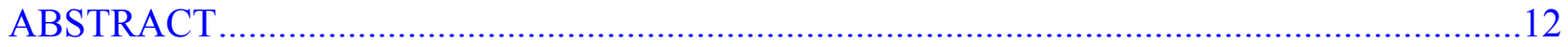

CHAPTER

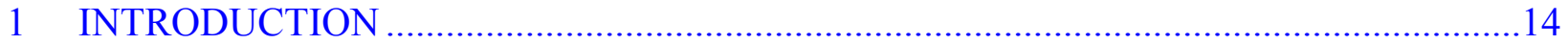





2.1.1 Skeletal Muscle Development .................................................................... 15

2.1.2 Myogenic Regulatory Factors (MRFs) ......................................................... 16

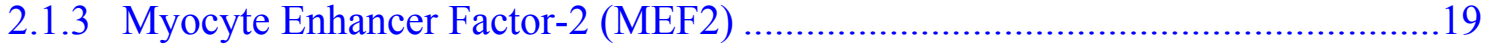

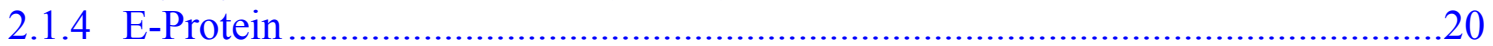

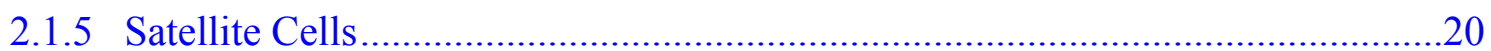

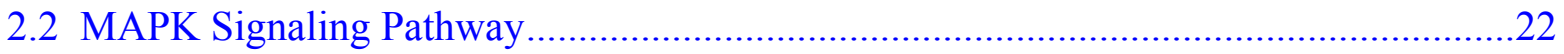

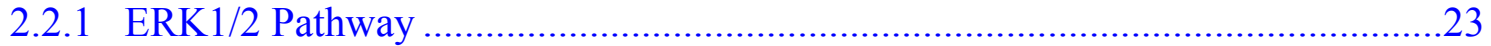

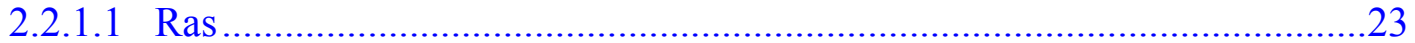

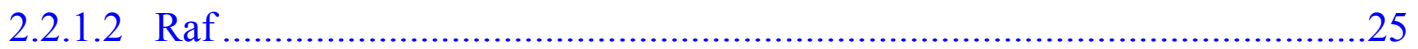



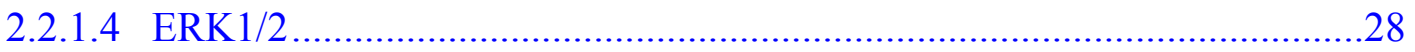

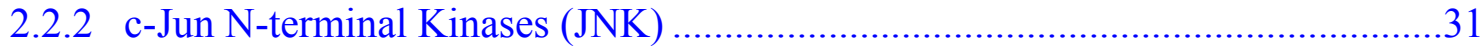

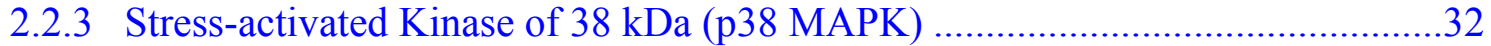

2.2.4 Extracellular Signal-regulated Kinase 5 (ERK5) .............................................33

2.3 Skeletal Muscle Growth and Hypertrophy: A Brief Overview .....................................33

2.3.1 Introduction of Skeletal Muscle Hypertrophy ..................................................33

2.3.2 Factors Regulate Skeletal Muscle Hypertrophy ..............................................34

2.3.3 Growth Factors and Signal Molecules that Promote Muscle Hypertrophy..........34

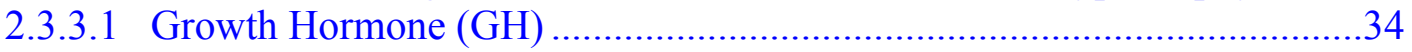

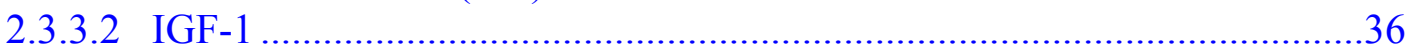

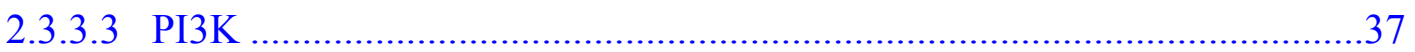

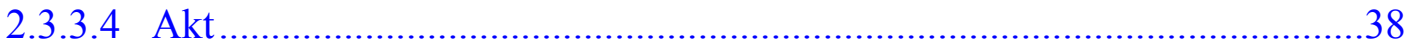

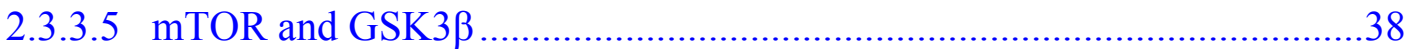

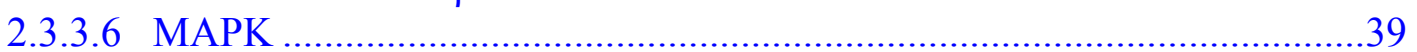

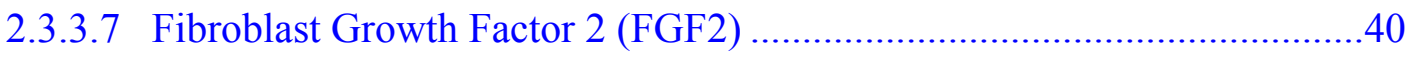

2.3.3.8 Hepatocyte Growth Factor (HGF) .................................................... 40 
2.3.4 Growth Factors and Cytokines that Inhibit Muscle Hypertrophy .......................41

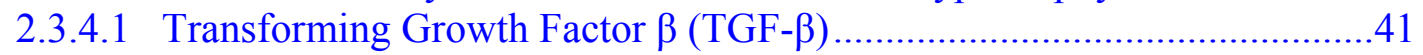

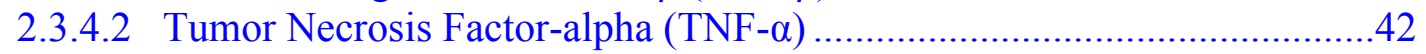

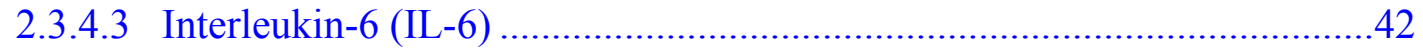

2.4 Summary of ERK1/2 Effects on Skeletal Myogenesis............................................43

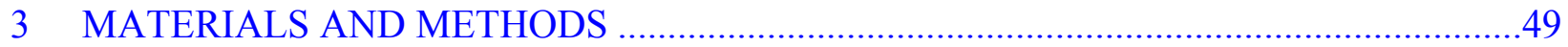

3.1 Cell Culture, Plasmids, and Transfection ..........................................................49

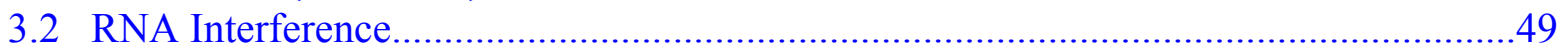



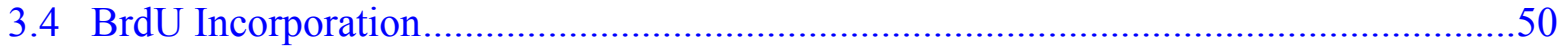



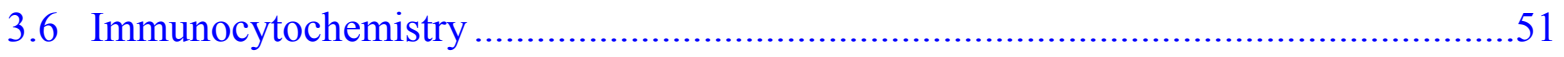

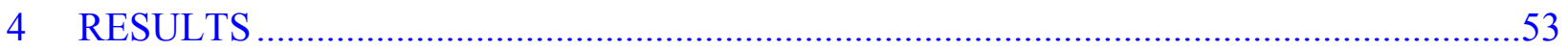



4.2 Creation and Validation of ERK1 and ERK2 siRNA...........................................54

4.3 Optimal Myoblast Proliferation Requires One Functional ERK Enzyme.....................54

4.4 ERK2 is Necessary for Efficient Myofiber Formation................................................55

4.5 ERK2 Knockdown Inhibits Myogenin Protein Expression.........................................56

4.6 IGF-I Signaling Partially Restores Myogenin Expression and Myofiber Formation.....57

4.7 FGF2 Does Not Signal Exclusively through Either ERK1 or ERK2 to Inhibit

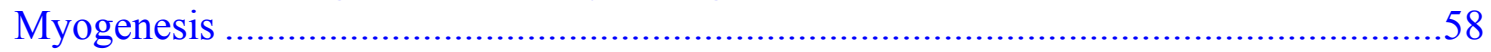



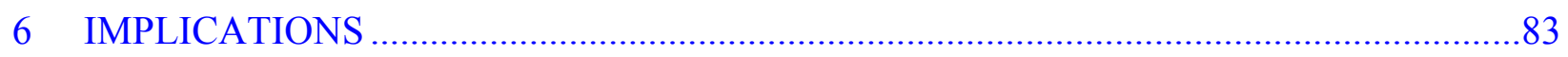



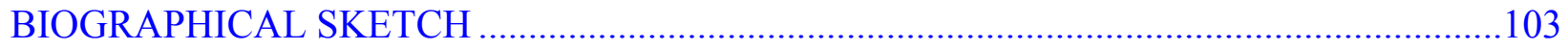




\section{LIST OF TABLES}

$\underline{\text { Table }}$

page



2-2 Summary of MAPK knockout mice phenotypes ..................................................46

2-3 Regulatory factors of skeletal muscle hypertrophy ...........................................4 


\section{LIST OF FIGURES}

$\underline{\text { Figure }}$

page



2-2 Signaling pathway involved in IGF-I induced skeletal muscle hypertrophy...................48

4-1 C2C12 myoblasts transduced with pSIRENsiERK1 and pSIRENsiERK2...................60

4-2 C2C12 myoblasts transduced with pSIRENsiERK1 or pSIRENsiERK2 does not inhibit ERK1/2 expression.

4-3 C2C12 myoblasts stable expressing single siERK1 or siERK2 does not inhibit ERK1/2 expressio..

4-4 Stable expression of siRNA directed against ERK1 or ERK2 reduces ERK1/2 protein levels.

4-5 Knockdown of ERK1 or ERK2 affects AP1 luciferase activity...................................64

4-6 Knockdown of ERK1 or ERK2 does not prevent myoblast proliferation......................65

4-7 Knockdown of ERK1 or ERK2 does not affect the mitogenic response.......................66

4-8 ERK2 deficiency leads to myogenic arrest..........................................................67

4-9 ERK2 deficiency leads to repression of differentiation and fusion of myoblasts.............68

4-10 Treatment with PD98059 inhibits activation of ERK1/2 and active ERK1/2...............69

4-11 Treatment with PD98059 does not affect C2C12siERK2 differentiation. ......................70

4-12 ERK2 deficiency causes a reduction in myogenin protein expression..........................71

4-13 ERK2 deficiency causes reducted myogenin expression in C2C12siERK2 myoblasts is partially restored by IGF-I treatment.

4-14 IGF-I treatment improves the differentiation capabilities of C2C12siERK2 myoblasts.

4-15 Myotube fusion index of IGF-I treated myoblasts.................................................... 74



4-17 ERK2 insufficiency does not disrupt IGF-I induced Akt phosphorylation. .....................76 
4-18 FGF2 requires one functional ERK isoform to inhibit myogenic differentiation.............77

4-19 Differentiation index of FGF2 treated myoblasts.. ......................................................78

4-20 FGF2 inhibits myogenic differentiation through either ERK isoform............................79 


\section{LIST OF ABBREVIATIONS}

\begin{tabular}{|c|c|}
\hline AP-1 & activator protein 1 \\
\hline bHLH & basic helix-loop-helix \\
\hline $\mathrm{BMK}$ & big mitogen-activated kinase \\
\hline BMP & bone morphogenetic protein \\
\hline Cdk & cyclin D-dependent kinase \\
\hline $\mathrm{CR}$ & conserved region \\
\hline DAPI & 4,6-diamidino-2-phenylindole \\
\hline $\mathrm{ED}$ & embryonic day \\
\hline eIF & eukaryotic initiation factor \\
\hline ERK & extracellular signal-regulated kinase \\
\hline FBS & fetal bovine serum \\
\hline FGF & fibroblast growth factor \\
\hline GDF & growth and differentiation factor \\
\hline GFP & green fluorescent protein \\
\hline $\mathrm{GH}$ & growth hormone \\
\hline GHR & growth hormone receptor \\
\hline GSK & glycogen synthase kinase \\
\hline HGF & hepatocyte growth factor \\
\hline HS & horse serum \\
\hline Id & inhibitor of differentiation/DNA binding \\
\hline IGF & insulin-like growth factor \\
\hline IGFBP & IGF binding protein \\
\hline
\end{tabular}




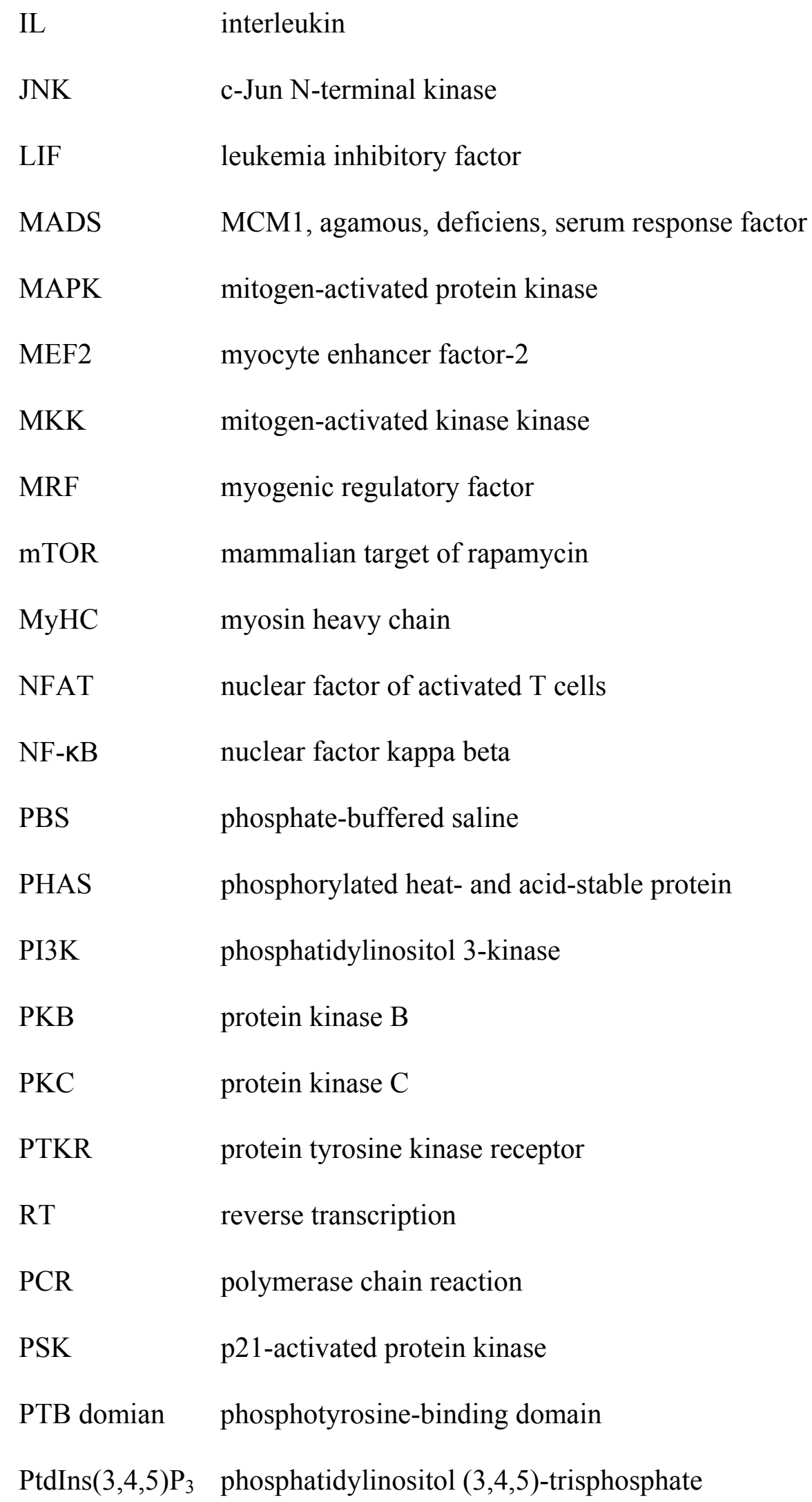




$\begin{array}{ll}\text { RSRF } & \text { related to serum response factor } \\ \text { SAPK } & \text { stress activated protein kinase } \\ \text { SH } & \text { src homology region } \\ \text { SOS } & \text { son of sevenless } \\ \text { STAT } & \text { signal transducers and activators of transcription } \\ \text { TGF } & \text { transforming growth factor } \\ \text { TnI-Luc } & \text { troponin I luciferase } \\ \text { TNF } & \text { tumor necrosis factor }\end{array}$




\begin{abstract}
Dissertation Presented to the Graduate School of the University of Florida in Partial Fulfillment of the Requirements for the Degree of Master of Science
\end{abstract}

\title{
ERK2 IS REQUIRED FOR EFFICIENT TERMINAL DIFFERENTIATION OF SKELETAL MYOBLASTS
}

By

$\mathrm{Ju} \mathrm{Li}$

May 2007

Chair: Sally Johnson

Major: Animal Sciences

Terminal differentiation of skeletal myoblasts involves alignment of the mononucleated cells, fusion into multinucleated syncitia, and transcription of muscle-specific genes. Myogenesis in vivo is regulated partially by IGF-I initiated signaling that results in activation of an intracellular phosphatidylinositol 3 kinase (PI3K) signaling cascade. Downstream signaling through the Raf/MEK/ERK axis, a pathway initiated by IGF-I, also is implicated in the regulation of muscle formation. The involvement of ERK1 and ERK2 during myogenesis was examined in $\mathrm{C} 2 \mathrm{C} 12$ myoblasts. $\mathrm{C} 2 \mathrm{C} 12$ myoblasts stably expressing a small interfering RNA (siRNA) directed against ERK1 or ERK2 were created. Both of the kinases were reduced to trace levels as measured by Western blot for total ERK and retained the capacity to become phosphorylated. The C2C12siERK2 knockdown myoblasts failed to fuse into multinucleated myofibers. By contrast, cells expressing a scrambled siRNA or ERK1 siRNA fused into large multinucleated structures. The block to muscle formation did not involve continued cell cycle progression or apoptosis. The C2C12siERK1 myoblasts expressed an increased amount of ERK2 protein and formed larger myofibers in response to IGF-I treatment. Interestingly, IGF-I treatment of $\mathrm{C} 2 \mathrm{C} 12 \mathrm{ERK} 2$ knockdown myoblasts did not reinstate the myogenic program 
arguing that ERK2 is required for differentiation. These results provide evidence for ERK2 as a positive regulator of myogenesis and suggest that ERK1 is dispensable for myoblast proliferation and differentiation. 


\section{CHAPTER 1 \\ INTRODUCTION}

The ERK1/2 MAPK signaling pathway is involved in multiple cellular processes including cell growth, proliferation, differentiation and survival. In skeletal muscle, Raf/MEK/ERK and PI3K/Akt cascade are downstream pathways of IGF-I-mediated skeletal muscle hypertrophy. Activation of ERK1/2 has a dual function in myogenesis. Low levels of Raf activity stimulates myoblast differentiation, and high levels of Raf activity inhibits myoblast differentiation [193]. Importantly, sufficient Raf activity to evoke ERK2 phosphorylation is coorelated with improved myocyte formation, while activation of ERK1 is associated with inhibition of myogenesis. The separable function of ERK1 and ERK2 during myogenesis was examined in C2C12 myoblasts. C2C12 myoblasts stably expressing small interfering RNAs direct against ERK1 and ERK2 were created, and their ability to form mature muscle cells was examined.

The objectives of this work were to (1) identify the distinct effects of ERK1 and ERK2 during myogenesis, (2) characterize the involvement of ERK1/2 in IGF-I induced myogenesis and (3) test the necessity of ERK1/2 in FGF2 stimulated mitosis. 


\section{CHAPTER 2 \\ LITERATURE REVIEW}

\subsection{Sketal Muscle System}

Skeletal muscle is the most abundant tissue in the human body and accounts for more than $50 \%$ of the total mass. This tissue serves as a major site of metabolic activity and as a protein reservoir. Skeletal muscle cells are cylindrical shaped, striated muscle, facilitating movement via contraction to apply force to bones and joints. Skeletal muscle maturation can be subdivided into myogenic determination, myoblast proliferation and terminal differentiation. A number of growth factors, signaling molecules and transcription factors are involved in skeletal muscle maturation. Thus, skeletal muscle presents a perfect model system to study cellular signal transduction.

\subsubsection{Skeletal Muscle Development}

All vertebrate skeletal muscles (except head muscles) are derived from progenitor cells contained within somites which arise by segmentation of paraxial mesoderm on either side of neural tube and notochord (reviewed in [18]). Somites also give rise to other tissues, including skeletal and connective tissue. During embryonic development, some pluripotent mesodermal cells are committed to the myogenic lineage, which is regulated by the cell fate determinants Hedgehog and Wnt family members [98]. These myogenic cells proliferate and in some cases migrate until there are extracellular signals from surrounding tissues including the neural tube and the lateral ectoderm, which make them withdraw from the cell cycle and undergo terminal differentiation. Subsequently, muscle-specific genes are expressed and mononucleated myoblasts fuse to each other to form the multinucleated syncytium.

The onset of muscle formation in the mouse embryo is called primary myogenesis. After embryonic day (ED) 14 in the mouse, secondary muscle fiber formation occurs [216]. As a 
result, adult skeletal muscles are composed of a mixture of myofibers with different physiological characteristics, from a slow-contracting type to a fast-contracting type, and the proportion of each fiber type within a muscle determines its overall contractile properties. There are several signaling pathways involved in these later stages of muscle development, but the molecular control mechanisms are still unclear.

\subsubsection{Myogenic Regulatory Factors (MRFs)}

During development of skeletal muscle, a group of myogenic transcription factors (myogenic regulatory factors, MRFs), play a significant role in lineage determination and differentiation [194]. MRFs (MyoD, myf5, myogenin and MRF4) are basic helix-loop-helix (bHLH) transcription factors. The HLH domain of the MRFs is responsible for dimerization with E-proteins. These heterodimers bind to the consensus CANNTG recognization site, which is found in the promoters and enhancers of many muscle-specific genes, leading to transcription of these genes.

$M y o D$ was the first MRF isolated and initially was regarded as a master regulatory gene due to its ability to convert non-muscle cells to the myogenic lineage [194]. The gene product is expressed early during development and likely participates in establishment of the skeletal muscle lineage [163]. Gene ablation studies indicate that loss of MyoD does not cause striking developmental abnormalities or functional deficits in the musculature [157]. Examination of the MRF gene expression patterns in the $M y o D^{(-/)}$mice reveals an increase in myf-5 mRNA levels. Thus, myf-5 may compensate for MyoD and provide normal myogenesis. Indeed, mice null for both $M y o D$ and $M y f-5$ are completely devoid of myoblasts, hence demonstrating the importance

of these early MRFs for commitment of multipotent somitic cells to the myogenic lineage [158]. However, not all of the effects of MyoD can be replaced by Myf-5. MyoD ${ }^{(--)}$mice display deficiencies in muscle regeneration following injury [118]. Satellite cells isolated from these 
animals proliferate in culture at rates comparable to wildtype myoblasts but $M y o D^{(-)}$myoblasts demonstrate abnormalities in the differentiation program [33]. A delay in myofiber formation is detected which may be attributed to maintenance of the myoblasts in a proliferative state [198]. Alternatively, satellite cells in vitro fail to express the late myogenic marker, $M R F 4$, which participates in activation of the myocyte gene program [33].

$M y f-5$ is recognized as an early marker of the myoblast lineage, similar to MyoD. Myf-5 mRNA is first detected in the dermamyotome compartment of the somite at ED8.5 in the mouse and maintained into adulthood [135]. Interestingly, Myf-5 mRNA also is detected in distinct regions of the brain suggesting that the bHLH factor is not muscle-restricted [37]. However, no measurable amounts of Myf-5 protein are observed in the developing neural areas possibly accounting for the lack of myogenic conversion in these tissues. Expression of Myf-5 is regulated in part by Pax3, a transcription factor that directs migration of myoblasts into the developing limbs [11]. Targeted deletion of the gene does not compromise embryonic viability. Mice are born with apparently normal musculature but die within minutes of birth as a consequence of rib malformities [20]. Due to its early expression pattern, Myf-5 typically is thought of as a lineage determination factor. The protein is often associated with putative quiescent satellite cells in mice and may play an important regulatory role in maintaining the myogenic lineage of these muscle stem cells [31].

MRF4 exhibits a biphasic expression pattern with transcripts initially detected at ED9.0 in the somite followed by a second peak during fetal development at ED16.0 [16]. Early detection of mRNA transcripts for MRF4 is coincident with $M y f-5$ with speculation that MRF4 may regulate transcription of Myf-5 [175]. The closely linked MRF genes also share a common regulatory element that contributes to their synchronous expression [175]. Because the two genes 
are positioned near one another on mouse chromosome 10, early homologous recombination experiments deleting $M R F 4$ were confounded with $M y f-5$ defects leading to variable phenotypes [133]. The initial MRF4 null mouse demonstrated no obvious muscle defects but rib deformities were apparent [93]. However, a second knockout mouse died immediately at birth with a severely truncated lower rib pair [19]. And, a third MRF4 null allele results in an intermediate phenotypic rib defect [139]. The rib malformations are reminiscent of those found in the $M y f-5$ knockout mouse. Closer examination of the deleted regulatory regions revealed that a cis element necessary for Myf-5 expression was disrupted to varying degrees in the MRF4 knockouts. Those animals with severe rib abnormalities and suffering perinatal lethality failed to direct the correct spatio-temporal expression of $M y f-5$ [212].

The final member of the MRF family is myogenin. Myogenin is expressed later than Myf5, MyoD or MRF4 with transcripts detected in the myotomal myoblasts at ED10.5 in the mouse [25]. Unlike mice devoid of the other MRFs, deletion of myogenin produces an animal with severe muscle defects. Myogenin null animals die within moments of birth due to insufficient diaphragm musculature $[73 ; 129]$. Histological examination of the mice demonstrates virtually no skeletal muscle exists in these mice. Expression of $M y o D$ and $m y f-5$ is unaffected and the animals contain the normal complement of myoblasts. Thus, myogenin is requisite for fusion of the myoblast precursors into the multinucleated contractile-competent structures. The necessity for myogenin does not extend into adulthood. Deletion of myogenin after completion of embryonic muscle formation causes a generalized reduction in body size [92]. However, the mice contained a proportional amount of skeletal muscle and the muscle was able to increase in size. This leads to the speculation that myogenin, and perhaps the entire family of MRFs, have very little to do with postnatal muscle growth. 


\subsubsection{Myocyte Enhancer Factor-2 (MEF2)}

Along with the MRFs, the myocyte enhancer factor-2 (MEF2) family also plays a role in skeletal, cardiac and smooth muscle myogenesis. The MEF2 family, also called Related to Serum Response Factor (RSRF), has four members (MEF2A, MEF2B, MEF2C and MEF2D), which are expressed in all developing muscle cell types [65]. MEF2 proteins have an identical Cterminal activation domain and N-terminal MCM1 agamous defeciens serum response factor (MADS) domain. The MADS domain serves for DNA binding and dimerization with accessory factors. MEF2 proteins bind a conserved A/T-rich DNA sequence in the control regions of a majority of muscle-specific genes and activate their expression during embryogenesis [45].

Previous studies indicated that muscle-specific gene expression and myogenesis are regulated by a combination of MRFs and MEF2s, and the DNA-binding domains of these factors mediate their interactions. MEF2 factors can cooperate with heterodimers of MRFs and E protein, and this interaction plays an important role in promoting myogenesis [123]. In addition to interacting with MRFs, MEF2s are shown to establish protein-protein association with several other transcription factors. This is important for MEF2 to transmit signals from cell membrane to downstream early genes and stress-response genes [45]. For example, transcriptional activation of the myoglobin promoter in striated muscle requires interaction with MEF2 and Sp1 [66].

MEF2s and MRFs can synergistically activate gene expression, which is important for MEF2s regulation of terminal differentiation. In flies, deletion of single $M E F 2$ gene results in an inability of muscle cells to differentiate [106]. In mice, targeted inactivation of $M E F 2 C$ gene is embryonic lethal due to severe defects in cardiac development [107]. However, there is no defect in skeletal muscle in these MEF2 deficient animals, possibly because different subtypes of MEF2s are expressed in skeletal muscle and compensate for lack of each other. In addition, 
transgenic mice expressing a MEF2 regulated lacZ reporter gene show that MEF2 activity is high during embryonic development but it is undetectable after birth [130].

\subsubsection{E-Protein}

The E-protein family (E12, E47, HEB and ITF-2) is another bHLH transcription factor family [97]. E-protein has a bHLH domain to form homodimer or heterodimer with MRFs family and two conserved transcriptional activation domains in the N-terminus.

E12 and E47 are alternative splice products of $E 2 A$ gene, which is ubiquitously expressed in many mammalian cells including skeletal muscle [10]. Lassar (1997) provided evidence that E12/E47 interact with myogenic HLH proteins to regulate myogenic program [97].

Cotransfection of E47 with MyoD enhances MyoD-activated genes transcription, and inhibition of E2A expression with antisense E2A transcripts displays low level of terminal differentiation. In addition, MyoD or myogenin can form complexes with E12/E47-like proteins, and E47 can change the phosphorylation state of MyoD [97]. E2A (-/-) mice are viable but defective in T-cell proliferation and B-cell differentiation [9;10]. HEB is found in L6 myoblasts, C2C12 myosatellite cells and postnatal hindlimb muscles, which suggests HEB may have a general role in the skeletal muscle development [28].

\subsubsection{Satellite Cells}

After maturity, most myoblasts form stable postmitotic muscle fibers that are incapable of proliferation. However, these fibers are associated with a pool of cells still capable of replication and regeneration of muscle tissue. In adult muscles, this subpopulation of cells is termed muscle satellite cells.

Muscle satellite cells are undifferentiated mononuclear myogenic cells located between the basal lamina and sarcolemma [214]. They are the primary stem cell in adult skeletal muscle, responsible for postnatal muscle growth, hypertrophy and regeneration. Satellite cells are 
mitotically and metabolically quiescent and transcriptionally less active than myonuclei [167;172]. In mature muscle, most satellite cells are in a quiescent state. In response to exercise, muscle damage or degenerative muscle disease, satellite cells awaken and begin proliferating [126]. Following proliferation, some cells differentiate and fuse into the pre-existing myofibers, and some return to the quiescent state during the process of self-renewal [166].

The classical identification and definition of satellite cells was performed by electron microscopy [115]. This remains the indisputable method of detection of quiescent muscle stem cells. However, the method is costly, cumbersome, and unavailable for most laboratories. This led to the quest for alternative means of satellite cell identification. In the late-1980s, reports of immunocytochemical localization of satellite cells in vitro and in vivo began to emerge.

Desmin, a cytoskeletal protein unique to muscle, is expressed by rodent satellite cells during the initial culture period prior to entry into the proliferative phase [89]. Following trauma, many desmin immunopositive cells are present in the reforming muscle bed at a time of maximal satellite cell proliferation [5]. Over the years, additional methods of satellite cell identification have evolved. Cell surface molecules including a splice variant of CD34 and a muscle-specific integrin have been used to demarcate satellite cells [13]. M-cadherin, an adhesion molecule, is expressed in skeletal and cardiac muscle and neural tissue. The protein localizes to satellite cells in normal and regenerating skeletal muscle [77]. Syndecan-3 and -4, heparan sulfate proteoglycans found on the surface of multiple cell types, are abundant matrix components on satellite cells and may be useful tools for identification of these cells [32;34].

A subtractive library screen comparing cDNAs present in satellite cells and embryonic fibroblasts identified Pax7 as one of several genes unique to the putative muscle stem cell [168]. Pax7, a paired box transcription factor, is present in $\mathrm{G}_{0}$ satellite cells and absent in differentiating 
myoblasts. Gene ablation results in a mouse compromised in muscle growth owing to an absence of satellite cells. Based on this work, Pax7 is a true marker protein for satellite cells and expression of the transcriptional regulator is necessary for satellite cell form and function. The definition of Pax7 as a lineage marker for satellite cells remains unclear. Examination of tissues of $\operatorname{Pax} 7^{(--)}$pups indicates numerous satellite cells are present [136]. The absolute numbers of these cells declines as the animal matures but a minor population, substantially fewer than normal, is present in the adult. The presence of these cells may be attributed to a shared function with the paralogous gene, $\operatorname{Pax} 3$. $\operatorname{Pax} 3$ and $\operatorname{Pax} 7$ are co-expressed in many putative satellite cells in the postnatal musculature $[151 ; 152]$. Pax3 positive satellite cells undergo apoptosis in the Pax7 knockout animal suggesting that $\operatorname{Pax} 7$ is necessary for cell survival but dispensible for lineage specification [151]. Continued expression of Pax7 in satellite cells is necessary for survival of the $\mathrm{G}_{0}$ population but does not affect the myogenic gene program[215]. Pax7 is coexpressed with MyoD in proliferating satellite cells. Down-regulation of the gene coincides with differentiation. Interestingly, overexpression of Pax7 delays the onset of terminal differentiation but does not prevent the eventual formation of myofibers [215]. This is in contrast to Olguin and Olwin (2004) who reported that ectopic expression of Pax7 in satellite cells prevents $M y o D$ and myogenin expression and induces cell cycle arrest. The presence of $\operatorname{Pax} 7(+): \mathrm{MyoD}(+)$ myoblasts that incorporate BrdU in the regenerating bed of skeletal muscle argues that Pax7 does not alter either MyoD expression or proliferation in vivo [132].

\subsection{MAPK Signaling Pathway}

Mitogenic signal transduction is mediated by a protein phosphorylation and dephosphorylation cascade. One of the most important mitogen-induced signaling pathways is the mitogen-activated protein kinase (MAPK) cascade. 
Many growth factors activate receptor tyrosine kinases that transduce extracellular signals through the small G protein, Ras. Ras protein phosphorylates and activates MAP kinase kinase kinase (MAPKKK), which in turn activates MAP kinase kinase. Subsequently, MAPKK phosphorylates MAPKs on threonine and tyrosine residues in a conserved motif (Thr-X-Tyr) in the kinase domain, which is required for MAPK activation [21].

The MAPK pathway is very sensitive and an efficient transducer of signals due to two characteristics of MAPK cascade. First, the MAPK cascade can amplify signals, which means as the signals pass down. Downstream targets are more abundant than their upstream regulator. As an example, MEK1 is much more abundant than Raf-1 [47]. Another characteristics of the MAPK pathway is switch-like output, which allows the MAPK cascade to convert graded inputs into different outputs [51]. For example, high and low levels of Raf-1 have opposite effects in skeletal muscle differentiation [41]. This mechanism enables cells to filter noise and still respond to stimuli over threshold.

The MAPK signaling pathway is conserved from unicellular organisms such as bacteria to multicellular organisms such as humans, and it regulates diverse cellular functions including cell growth, proliferation, differentiation and apoptosis. In mammals, more than four groups of MAPKs are recognized that include two extracellular signal-regulated kinases (ERK1/2), three cJun N-terminal kinases (JNK1/2/3), four p38 protein kinases $(\mathrm{p} 38 \alpha / \beta / \gamma / \delta)$ and ERK5. Figure 2-1 shows the different MAPK signaling cascades, and Table 2-2 summarizes MAPK knockout mice phenotypes.

\subsubsection{ERK1/2 Pathway}

\subsubsection{Ras}

Mamalian genomes encode three ras genes that give rise to four protein products, N-Ras, H-Ras, K-Ras4A and K-Ras4B. These Ras isoforms are ubiquitously expressed, though ratios 
change from tissue to tissue [211]. Ras proteins can induce cell transformation through a number of effectors. Constitutive activation of Ras causes a large number of human cancers [49]. Ras family members are membrane localized small GTPase, which are associated with multiple signal transduction pathways that regulate different cellular functions.

The best characterized signaling pathway regulated by Ras is the ERK1/2 MAPK pathway. The pathway is activated following growth factor docking to protein tyrosine kinase receptors (PTKRs). PTKRs dimerize and autophosphorylate, which in turn allow cross phosphorylation of tyrosine residues in their cytosolic domain. These intrinsic phosphotyrosine domains serve as docking sites for Src homology region 2 (SH2) and the phosphotyrosine-binding (PTB) domain, which causes recruitment of son of sevenless (SOS) in the plasma membrane and subsequent binding to Ras. Once Ras is activated at the membrane, it recruits Raf- 1 and activates the downstream Raf-MEK-ERK pathway [124].

The mechanism underlying the Ras-imposed block to differentiation remains unclear. A series of Ras mutants were examined for their ability to invoke specific downstream signaling pathways to suppress myogenesis [146]. Ras alleles that initiate exclusive signaling through Raf, Rac or Rho all efficiently inhibit muscle gene transcription indicating that no single downstream effector pathway mediates the negative effects of Ras. Importantly, morphological transformation and inhibition of differentiation are mutually exclusive events [195]. Overexpression of RasG12V in muscle cells causes growth in soft agar that can be reverted by treatment with a chemical MEK inhibitor. However, these cells remain unable to express the myogenic gene program. Ras invoked signaling through protein kinase $\mathrm{C}$ may be a primary downstream pathway leading to inhibition of myocyte formation [49]. Treatment of myoblasts constitutively expressing RasG12V with a chemical inhibitor to a class of atypical protein kinase 
$\mathrm{C}$ molecules restores biochemical differentiation. However, the specific PKC isoform and its downstream effectors remain unknown.

Secretion of soluble proteins by Ras-transformed myoblasts may contribute to the block to muscle formation. Weyman and Wolfman (1997) collected spent medium from Ras-expressing muscle cells and demonstrated the presence of an acid-sensitive factor capable of inhibiting differentiation. The secreted protein does not induce ERK1/2 phosphorylation and does not signal through a TGF- $\beta$ receptor. No detectable FGF2, a potent inhibitor of myoblast differentiation, was present in the spent medium [196]. By contrast, Ras-expressing MM14 myoblasts proliferate faster and control myoblasts due to their ability to release more membranebound FGF2 [49]. Sequestering FGF2 suppresses proliferation but does not reinstate myogenesis. Thus, Ras inhibits muscle formation independent of continued cell cycle progression.

\subsubsection{Raf}

Raf is an oncogene first discovered as a retrovirus in 1983 [147]. Raf family members are cytosolic serine/threonine kinases that are activated by Ras. The Raf family (A-Raf, B-Raf, Raf1) share three conserved regions, CR1, CR2, CR3. The kinase domain is localized in CR3, and CR1 and CR2 are regulatory domains [69]. Raf-1 is ubiquitously expressed, while B-Raf is predominate in neuronal tissues and testis, and A-Raf is abundant in urogenital tissue [122].

Raf-1 is a well-established Raf isoform. Raf-1 can promote invasive cell growth and induce cell transformation as well as Ras proteins [101]. However, regulation of Raf-1 is very complex, including protein-protein interaction, phosphorylation of tyrosine, threonine and serine residues and subcellular localization [125]. Raf-1 phosphorylation is affected by different protein kinases, such as Src, PKC, PKB, and PSK (p21-activated protein kinase) [125]. 
Raf-1 is important in regulating cell growth and mitosis. High level of Raf kinase is sufficient to inhibit DNA synthesis and cell division, which converts mitotic cell cycling into cellular growth [90]. Raf-1 causes cell cycle arrest through induction of $\mathrm{p} 21^{\mathrm{Cip} 1}$, which in turn leads to inhibition of cyclin D- and cyclin E-dependent kinases and accumulation of hypophosphorylated $\mathrm{Rb}$ [169].In skeletal muscle satellite cells, a dominant negative Raf-1 mutant can block FGF-mediated stimulation of ERK1/2 as well as block cell proliferation. In these cells, Raf-1 is necessary for $\mathrm{G}_{1}$ progression but dispensable for $\mathrm{S}$ phase [83].

In skeletal muscle, Raf-1 regulates myoblast differentiation in a dose dependent manner [41;193]. At a low level Raf activity, there is an increase in differentiation, contractile protein expression and myocyte fusion. However, high level of Raf activity induces transformed morphology and inhibits myocyte formation, muscle-specific reporter expression and apoptosis [41;193]. Raf-1 also is involved in FGF-induced repression of differentiation [83]. Constitutive expression of Raf-1 suppress $M y o D$ expression [67]. And persistent activation of Raf-1 inhibits MEF2 accumulation in nuclei. This results in decreased myogenin activity, reduced muscle protein expression and inhibition of myoblast fusion [82;199].

Evidence suggests Raf-1 has other functions independent of activating MEK and ERK kinases, such as regulating cell survival, cell apoptosis, and cell cycle [12]. For example, Raf-1 can inhibit apoptosis signaling by binding with proapoptotic kinase MST2 and forming MST2/Raf-1 complex [131].

The necessity of Raf signaling in skeletal muscle in vivo is unclear due to lethality issues. A-Raf knockout mice are born alive and of normal size, but stop growing after 2-3 days and die between day7 and day 21 due to neurological and gastrointestinal abnormalities [145]. B-Raf null mice die from vascular defects during mid-gestation, and $B-R a f^{(-/)}$embryos have increased 
apoptosis in differentiated endothelial cells [202]. Ablation of Raf-1 results in embryonic lethality of mice, with placental defects as well as abnormal tissue development. In these mutant mice, most organs appeare normal, however, the eyelids fail to fuse properly, dermis and epidermis are abnormally thin and poorly differentiated, and the lungs are smaller and fail to inflate at birth. The time of embryonic death of Raf-1 deficient mice varies depending on the genetic background [201]. Fibroblasts isolated from Raf- 1 knockout embryos had reduced proliferation in response to serum [201]. Interestingly, ERK1/2 phosphorylation in response to mitogens is not impaired, which indicates ERK1/2 can be activated in a Raf-independent mechanism [201].

\subsubsection{MEK1/2}

Genetic studies show two MEK homologs, MEK1 and MEK2 are present in mammals, which share $80 \%$ homology except at the amino terminus [218]. They activate ERK1/2 by phosphorylating the TEY domain with equal competency.

MEK1 null mice are recessive lethal at day 10.5 due to a failure to establish a functional placenta. These mice are small and show signs of necrosis in some tissues [62]. The placenta defects also are found in Raf-1 knockout mice, which suggests that the Raf-MEK axis is necessary for proper placenta development [201]. However, MEK2 knockout mice are viable with no obvious deficiencies [14]. Comparing the phenotype of ERK1/2 and MEK1/2 knockout mice, the results show there are possible relationships between $M E K 1$ and $E R K 2$ in embryonic development[62;74]. A scaffold protein MEK partner 1 was identified as a protein that binds specifically with MEK1 and ERK1, and facilitates their activation [164].

To further determine the effects of MEK activation in vivo, tissue-specific transgenic mice were created. When active MEK1 is over-expressed in cardiac muscle under the control of cardiac specific $\alpha$-myosin heavy chain promoter, the transgenic animals show a $50 \%$ increase in 
heart size and the cardiocytes are resistance to apoptosis [23]. Constitutive expression of the MEK1 in the lens or skin cause increases in cell numbers and cell size related to tissue growth and hypertrophy [64;165].

In skeletal muscle, MEK is required for myoblast and satellite cell proliferation [83]. Treatment of MM14 myoblast with MEK inhibitor, PD98059, or expression a dominant negative MEK mutant blocks FGF-mediated stimulation of ERK1/2 and prevents $\mathrm{G}_{1}$ to $\mathrm{S}$ phase transition [83]. MEK1 has a strong negative effect on myogenesis. Myoblasts over-expressing constitutively active MEK1 fail to fuse and transcribe muscle gene [143]. MEK1 translocate to the nucleus, where it may bind the transcriptional activation domain of $\mathrm{MyoD}$ to repress its action. MEK1 also is involved in IGF-I and FGF2 induced repression of differentiation [197]. Treatment with PD98059, can partially reverse the negative effects of FGF2 and IGF-I. However, enthusiasm for these results is tempered due to the validity of the myoblast model. IGF-I inhibits differentiation of 23A2 myoblasts, a phenomena unique to these cells [179;197]. On the other hand, ERK is activated in myogenic cells [67]. A MEK1 inhibitor can block the MyoD induced myogenic program in fibroblasts, which suggest MEK is activated in the process of differentiation. Constitutive expression of MEK1 enhances the transcriptional activity of MyoD in fibroblasts. The importance of MEK1 during myogenesis requires further experimentation.

\subsubsection{ERK1/2}

ERK1 and ERK2 are two MAPK proteins 75\% identical in amino acid sequence and similar in structure [174]. They have two phosphorylated sites, tyrosine and threonine, which can be activated by MEK1 or MEK2 [3]. ERK1/2 are ubiquitously expressed, but their relative abundance in different species or tissues are variable. ERK1/2 respond to different stimulus and 
induce different responses. In fibroblasts, ERK1 can be activated by serum, growth factors, cytokines, certain stresses, ligands for cell membrane receptors and transforming agents [104].

When ERK1 and ERK2 are activated, they translocate from the cytoplasm to the nucleus. This stimulus-dependent nuclear localization appears to be crucial for multiple cell functions, such as morphological transformation and cell differentiation in PC12 cells [35]. The interaction between MEK1/2 and ERK1/2 plays a prominent role in ERK1/2 translocation and nuclear accumulation. MEK1/2 N-terminus acts as a cytoplasmic anchor. When ERK1/2 are activated, MEK1/2 and ERK1/2 disassociate, and ERK1/2 are transported to the nucleus [59;60].

The ERK1/2 signal pathway is essential for cell growth. ERK1/2 increases nucleotide synthesis, affects the transcription of many genes through transcription factor activation and chromatin phosphorylation, stimulates protein synthesis and controls the cell cycle. Mitogenic stimulation of cells causes ERK1/2 phosphorylation and translocation from cytoplasm to the nucleus. This process is necessary for initiation of DNA synthesis and progression from $\mathrm{G}_{0}$ to $\mathrm{S}$ phase [22]. Phosphorylation of transcription factors by ERK1/2, such as Elk1, regulate the expression of cyclin D1 and facilitates cell cycle re-entry [99;184]. Interestingly, MEK1 activation results in transient ERK activity that promotes cell cycle transition from $\mathrm{G}_{1}$ to $\mathrm{S}$ phase, while MEK2 produces sustained ERK activity causing cells to arrest in $\mathrm{G}_{1}$ phase [156;184]. Besides the $\mathrm{G}_{1}$ checkpoint, ERK1/2 also regulates $\mathrm{S}$ phase progression. ERK1/2 can activate elonglation factor, E2F, which promotes expression of cyclin $A$ and in turn stimulates DNA synthesis [203]. Furthermore, ERK1/2 participates in $\mathrm{G}_{2}$ phase chromosome condensation. ERK and p38 can phosphorylate mitogen- and stress-activated protein kinase, which phosphorylates histone $\mathrm{H} 3$ to promote chromosome condensation [40]. The ERK 1/2 also promote cell differentiation in multiple cell lineages, such as fibroblasts, neuronal cells, myoblasts, 
adipocytes, oocytes, T cells, photoreceptor cells [112]. And ERK1/2 play an important role in cell apoptosis. High level of ERK1/2 activation protects cells from apoptosis induced by anchorage-independence and serum removal. However, low level of ERK1/2 activity can force the cells to apoptose [100].

The ERK1/2 pathway is an important pathway involved in both mitogenesis and myogenesis. Growth factors, such as leukemia inhibitory factor (LIF), IGF-I, FGF2 and transforming growth factor $\beta$ (TGF- $\beta$ ) regulate skeletal muscle through ERK1/2 signaling cascades [2;81;179;193;209]. However, the precise mechanisms invoking ERK1/2 phosphorylation are not clear. Most reports support that activation of ERK1/2 pathway is responsible for the negative regulation of skeletal myogenesis $[2 ; 2 ; 2 ; 42 ; 44 ; 81 ; 82 ; 143 ; 146 ; 179 ; 194 ; 195 ; 200 ; 209]$, but others indicate the ERK1/2 pathway is used for positive skeletal myogenesis [67]. The contrasting results may be due to ERK signaling intensity and temporal activation during myogenesis [41;193].

ERK1 and ERK2 share 90\% identity at the mRNA level and 75\% identity at the amino acid level. They have similar activation process and nearly identical downstream substrates [174]. However, recent work demonstrates that ERK1 and ERK2 have different functions. ERK1 knockout mice are viable and fertile, with only a minor defect in thymocyte development. Fibroblasts from these animals proliferate normally in response to serum, while thymocytes from these animal shows reduced proliferation and slow rate of maturation into single positive (CD8+ or CD4+) thymocytes [137]. In these mice, ERK2 can compensate for most of the functions of ERK1 except for the thymocyte development. The ERKI(-/-) mice also have an enhanced longterm memory, suggesting a function for ERK1 in the brain self-adaptation system [116]. On the other hand, ERK2 knockout embryos are deficient in mesoderm formation. BrdU incorporation 
shows ERK2 affects differentiation instead of proliferation. The ERK2 knockout embryos have an increased level of ERK1 phosphorylation, but ERK1 can not compensate for loss of ERK2 in vivo as it does in vitro [210]. Also ERK2 mutant embryos die early (E8.5) in mouse development due to a failure to form the ectoplacental cone and extra-embryonic ectoderm, which give rise to mature trophoblasts [159]. ERK2 knockout mice also are embryonic lethal at day 6.5 due to abnormal placenta development [74]. These results suggests ERK2 is necessary for placenta development, trophoblast proliferation and mesoderm differentiation[74;159;210]

\subsection{2 c-Jun N-terminal Kinases (JNK)}

JNKs are an important MAPK family that are involved in the regulation of cell proliferation, oncogene transformation and programmed cell death. JNKs are phosphorylated and activated by the JNK kinase 1 (JNKK1; MKK4) and JNK kinase 2 (JNKK2; MKK7), which are activated by a variety of up-stream MAPKKKs. JNKs have similar MAPK cascade as ERKs, however, unlike ERK1/2, the JNKs are activated by stress stimuli. Activated JNKs phosphorylate downstream transcription factors, such as c-Jun and ATF-2 [121].

The JNK family has three members: JNK1, JNK2 and JNK3. The three JNK isoforms must have overlapping functions in embryonic development because all individual $J N K$ gene knockout mice and $J N K 1 / J N K 3$ or $J N K 2 / J N K 3$ double mutants are viable and develop normal [94]. JNK3(/-) adult mice develop neuronal apoptosis, which indicates the JNK3-mediated signaling pathway is involved in neuroprotection [208]. Mice lacking both $J N K 1$ and $J N K 2$ are embryonic lethal at day 11 and display an open neural tube [94;161]. Embryonic fibroblasts devoid of JNK1 and $J N K 2$ are resistant to UV-stimulated apoptosis [180]. These results indicate JNK1/2 play an essential role in regulating stress-induced apoptosis. Furthermore, loss of both $J N K 1$ alleles and one $J N K 2$ allele results in an exencephalic phenotype that suggests JNK gene dosage might be critical for its function [161]. Together, these results show JNK3 plays a pro-apoptotic role in 
response to stress, while $J N K 1$ and $J N K 2$ are essential in both pro-apoptotic and anti-apoptotic process during neuron morphogenesis.

During skeletal muscle differentiation, JNK activity is up-regulated, and inhibition of JNK activity dramatically inhibits myoblast differentiation [91]. Different from ERK1/2, JNK inhibitors repress myogenesis through induction of apoptosis, and activation of c-Jun and p53 transcription factors [91]. Overexpression of JNK in skeletal muscle results in a significant increase in the basal phosphorylation state of several signaling molecules, such as ERK1/2 and PKB [58].

\subsubsection{Stress-activated Kinase of $38 \mathrm{kDa}$ (p38 MAPK)}

p38 MAPK also is referred to as a stress activated protein kinase [213]. p38 is activated by various stresses, hormones and inflammatory cytokines that are induced by MKK3 and MKK6 phosphorylation. MEK3 favors phosphorylation of $\mathrm{p} 38 \alpha$ and $\mathrm{p} 38 \beta$, while MEK6 phosphorylates all p38 members. MEK3/6 also can phosphorylate JNK isoforms with lower affinity [46].

p38 MAPKs have four isoforms, p38 $\alpha, \mathrm{p} 38 \beta, \mathrm{p} 38 \gamma$ and $\mathrm{p} 38 \delta$. Of these four subtypes, $\mathrm{p} 38 \alpha$ is the best characterized and it is expressed in most cell types. $p 38 \alpha$ knockout mice are embryonic lethal due to defective placental angiogenesis [1;127]. Compared to p38 $\alpha$-deficient mice, both $p 38 \beta$ and $p 38 \gamma$ knockout mice are viable with a normal life span and show no obvious phenotype [95]. Thus, p38 $\alpha$ has a specific function in placental development, and it can compensate for the lack of $\mathrm{p} 38 \beta, \mathrm{p} 38 \gamma$ and $\mathrm{p} 38 \delta$ isoforms.

p38 MAPK is a potent activator of myoblast differentiation and treatment with p38

inhibitors prevents myoblast fusion into myotubes as well as muscle specific gene expression [105]. There are many potential explanations for the positive effect p38 MAPK in skeletal myogenesis. p38 can phosphorylate E47 to induce MyoD/E47 association and subsequent muscle-specific gene transcription [110]. p38 activity also phosphorylates MEF2 activation 
domain and facilitates MEF2 and MyoD binding to a series of late muscle-specific gene promoters, and the expression of these genes can activate the p38 to move the cells to the early differentiation stage [142;204]. In mammalian myoblasts, there is crosstalk between p38 MAPK and the NF- $\mathrm{\kappa B}$ signaling pathway coordinately promote myogenesis [8]. p38 MAPK acitivity is required for the quiescent state of skeletal muscle satellite cells. Inhibition of p38 MAPK promotes myogenic cell cycle exit and inhibits differentiation [84]. p38 MAPK pathway also increases MEF2 transcriptional regulation during early mammalian somite development [39].

\subsubsection{Extracellular Signal-regulated Kinase 5 (ERK5)}

ERK5, also called big mitogen-activated kinase (BMK), is a special member of the MAPK family. ERK5 expresses in a wide range of tissues, especially in the cardiovascular system. ERK5 is phosphorylated by MEK5, which is activated by MEKK2 and MEKK3. ERK5 has a catalytic domain similar to ERK1/2, but a unique C-terminus that can interact with the MEF2 transcription factor family [87;207]. ERK5 can affect cellular activity through phosphorylation of the MADS box transcription factors and myocyte enhancer factor 2A and 2C (MEF2A, MEF2C) [88]. Although the ERK5 C-terminus functions as a MEF2 coactivator, its role in myogenesis is unknown [87]. ERK5 gene deletion mice are embryonic lethal due to defective blood vessel and myocardium $[150 ; 173 ; 206]$.

\subsection{Skeletal Muscle Growth and Hypertrophy: A Brief Overview}

\subsubsection{Introduction of Skeletal Muscle Hypertrophy}

Skeletal muscle hypertrophy is defined as an increase in muscle mass. On the other hand, decrease of muscle mass is called atrophy, which is a response to numerous diseases, such as diabetes, cancer, renal failure and AIDS [63]. In the adult animal, skeletal muscle hypertrophy is a result of an increase in the size of existing muscle fibers instead of an increase in numbers of fibers. 


\subsubsection{Factors Regulate Skeletal Muscle Hypertrophy}

Several intrinsic and extrinsic growth factors and stimuli promote or inhibit skeletal muscle hypertrophy (Table 1-3). The most common stimulus of muscle hypertrophy is exercise, which includes strength training and resistance exercise as a positive factor [48]. Nutritional factors including energy balance and dietary protein supplementation also are necessary for skeletal muscle hypertrophy [48]. Muscle injury and muscle aging are associated with muscle atrophy [48]. However, the most important factors that regulate skeletal muscle hypertrophy are hormones and growth factors, which initiate intracellular signaling pathways and stimulate myoblast proliferation, myocyte differentiation and muscle-specific protein synthesis. For example, testosterone, insulin and growth hormone are the main reasons for postnatal muscle hypertrophy [54].

\subsubsection{Growth Factors and Signal Molecules that Promote Muscle Hypertrophy}

\subsubsection{Growth Hormone (GH)}

Growth hormone $(\mathrm{GH})$ is a major regulator of body size and metabolism. Failure to synthesis or secret GH leads to short stature. On the other hand, hypersecretion of GH induces gigantism, if hormone is overproduced early in the life, or acromegaly, if oversecretion occurs in adulthood [54].

Growth hormone is associated with postnatal growth instead of prenatal growth. Although growth hormone receptor (GHR) exists in embryos, growth hormone does not play a necessary role in embryonic development. GH gene mutation in mice or ablation of the pituitary does not affect prenatal growth [56].

The "somatomedin hypothesis" demonstrates that pituitary GH (somatotropin) stimulates postnatal growth indirectly through stimulating the hepatic production of circulating peptide hormones (somatomedin), which then mediates the hormonal effects on target tissue. 
Somatomedin has an insulin-like action and promotes the incorporation of sulfate into cartilage [113]. Currently, somatomedin is referred to as insulin-like growth factor (IGF-I). The somatomedin hypothesis has been referred to the dual-effector theory. This theory proposes that GH directly stimulates the differentiation of precursor cells to certain cell types. The newly differentiated cells are more sensitive to the IGF-I than the precursor cells. Thus, initial direct action of GH leads to later IGF-I action in the target cells [78].

IGF-mediated actions of GH exist in different tissues, including fat cells, chondrocytes and skeletal muscle. Hypophysectomy causes a decrease in muscle mass and the level of myosin heavy chain mRNA decreases as well. Also GH treatment of hypophysectomized animals can partially restore these situations, such as increasing muscle mass and strength and decreasing body fat [111]. There is a loss in GH secretion as human aging, which is associated with decrease in muscle mass and strength. Injection of rhGH for men older than 60 can improve lean body mass and bone density [54]. However, GH can not be used as a general performance intensifier because GH injection can not increase muscle growth and strength for normal exercising people [54].

GH and IGF-I system constitute the major determinant of body size, and GH and IGF have independent functions in regulating the postnatal growth. The Igfl gene mutant and $G h r$ gene mutant mice both show retarded bone and muscle growth. GH can stimulate production of hepatic IGF-I, which is a principal source of circulation IGF-I. Loss of liver-specific IGF-I production lowers the concentration of IGF-I in blood reduces by $75 \%$, with no effect on muscle mass [171]. In the absence of GH, blood IGF-I levels are diminished, but the local IGF-I content (such as IGF-I produced by skeletal mucle) is unaffected. GH receptor and IGF-I double mutant mice are only $17 \%$ of normal size, which is more severe than either of the single mutants [113]. 


\subsubsection{IGF-1}

Insulin-like growth factor system includes two hormones (IGF-I and IGF-II), three receptors and six IGF specific binding proteins (IGFBP-1 to -6). Knockout experiment of different parts of IGF system indicates all components are very important in muscle growth and development [54].

Compared to IGF-II and insulin, IGF-I has a primary role in regulating skeletal muscle growth. Mice lacking $I G F-I$ exhibit growth deficiency. Depending on genetic background, some $I G F$ (-/-) mice die immediately after birth, while others survive and reach adulthood [109]. In contrast, transgenic mice over expressing human IGF-I have a 30 percent increase in body weight due to apparent increases in skeletal muscle and bone [114]. On the other hand, null mutation of igflr all die at birth of respiratory failure and exhibit a severe growth deficiency [109]. Expression of a dominant negative IGF-I receptor specifically in skeletal muscle induced muscle hypoplasia from birth to 3 weeks old, with decreased level of MyoD and myogenin. After grew to adulthood, these mice showed compensatory hyperplasia, with increased MyoD, myogenin, p38 and p21 levels [50].

IGF-I stimulates myoblast proliferation, myogenic differentiation and myotube hypertrophy in both cultured cells and in intact animals [54]. To balance the mitogenic and myogenic action on skeletal muscle cells, IGF-1 has a biphasic effect. Initially, IGF-1 inhibits expression of myogenin, a myogenic regulatory factor, which results in a proliferation response. Subsequently, IGF-1 switches to stimulate myogenin expression, which up-regulates differentiation as well as down-regulates proliferation [177]. It also is reported that a high concentration of IGF-I can inhibit myoblast differentiation as well as proliferation [197].

IGF-I is sufficient to induce skeletal muscle hypertrophy. IGF-I can induce myofiber hypertrophy in vitro by stimulating myoblast proliferation and fusion to established myofibers 
[186]. It also has been reported that an increase in muscle load can stimulate muscle hypertrophy with simultaneous increased expression of $I G F-1$ [43]. Expression of IGF-I in myoblasts can increase the expression of MRFs, such as MyoD and myogenin, and also stimulate contractile protein expression and myotube formation [27]. Mice overexpressing IGF-I in muscle, have at least twofold greater muscle mass compared with wild type mice. Thus indicates IGF-I stimulates skeletal muscle hypertrophy in vivo [27]. The mechanism for IGF-I signaling in myoblast proliferation is mediated primarily by ERK $1 / 2$ pathway, whereas myoblast differentiation prefers the PI3K pathway [29]. Figure 2-2 shows the signaling pathways involved in IGF-I induced skeletal muscle hypertrophy.

\subsubsection{PI3K}

Phosphatidylinositol 3-kinase (PI3K) is a lipid kinase, which phosphorylates the membrane phospholipids phosphatidylinositol -4,5-bisphosphate, producing phosphatidylinositol $(3,4,5)$-trisphosphate $\left[\operatorname{PtdIns}(3,4,5) \mathrm{P}_{3}\right]$. PtdIns $(3,4,5) \mathrm{P}_{3}$ is a lipid binding site for the serine/threonine kinase, Akt1 ( also known as protein kinase B) [96]. Once Akt1 is activated, it phosphorylates downstream substrates, which induces gene transcription and protein synthesis to promote cell proliferation and inhibit apoptosis [190].

PI3K activity is required for IGF-I mediated skeletal muscle hypertrophy. It has been reported that IGF-1 induces hypertrophy by activating the PI3K-Akt pathway, which causes activation of proteins that are required for protein synthesis [17;154]. Furthermore, pharmacological inhibition of PI3K activity prevents muscle hypertrophy induced by IGF-1 [85]. Therefore, PI3K activation is sufficient to induce skeletal muscle hypertrophy, and its activity is necessary for the IGF-1 induced hypertrophy. 


\subsubsection{Akt}

The Akt family, also called protein kinase B (PKB), is composed of three members, Akt1, Akt2 and Akt3 [96]. These three members share 80\% homology but have distinct functions [96].

Akt1 (-/-) mice are viable and smaller than wild type littermates, which suggests Akt1 is required for muscle growth and other tissue development [24]. Mice deficient in Akt2 are impaired in the ability of insulin to adjust the blood glucose and the animals have diabetes. Thus Akt2 is involved in glucose transport and maintenance of glucose homeostasis [26]. Akt1 and Akt2 are expressed in skeletal muscle and cooperate to promote muscle hypertrophy [96]. During work-induced muscle hypertrophy, there is an increase in endogenous Akt1 activity, as well as mTOR, which is a downstream target of Akt1 [17]. Expression of a dominant negative Akt1 blocks IGF-I induced muscle hypertrophy in vivo [154]. Transgenic mice with constitutively active Akt in adult skeletal muscle exist. In these mice, activation of Akt is sufficient to induce rapid and significant skeletal muscle hypertrophy, accompanied by activation of the downstream Akt/mTOR/p70S6 kinase protein synthesis pathway [96].

\subsubsection{5 mTOR and GSK3 $\beta$}

Akt1 is a key molecule in the IGF-I induced hypertrophy, because it can activate multiple downstream signaling, including the mammalian target of rapamycin (mTOR), p70S6 kinase (p70S6K), phosphorylated heat- and acid-stable protein 1 (PHAS-1, also known as 4E-BP1) and glycogen synthase kinase $3 \beta$ [154].

mTOR is a downstream substrate that has a central function in integrating growth factor stimulation with intracellular protein synthesis. Rapamycin, a mTOR inhibitor, blocks activation of downstream p70S6K stimulation by Akt1 and IGF-I [138;154;155]. Treatment of muscle cells with rapamycin can either inhibit the cell growth or decrease the mucle hypertrophy in vitro 
[138;154]. In vivo, treating the mice with rapamycin inhibits skeletal muscle hypertrophy induced by over expression of Akt1 [17]. In these mice, p70S6K activity decreases, while Akt1 activity does not change. These results indicate a linear signaling pathway during hypertrophy: Akt1-mTOR-p70S6K. On the other hand, activation of mTOR also inhibits PHAS-1, which is a negative regulator of the translation initiation factor eIF-4E [71]. Thus, mTOR is the signal molecule downstream of PI3K-Akt pathway in the IGF-I mediated hypertrophy. Active mTOR promotes protein synthesis through two distinct mechanisms, positively regulating the p70S6K pathway and negatively regulating PHAS-1 pathway.

GSK3 $\beta$ is a different substrate of Akt1, which also is involved in regulating skeletal muscle hypertrophy. Phosphorylation of Akt 1 inhibits GSK3 $\beta$ activity [36]. Expression of a dominant-negative form of GSK3 $\beta$ induces hypertrophy in skeletal myotubes [154]. GSK3 $\beta$ inhibits protein translation initiation through eIF-2B protein [72]. Therefore, PI3K-Akt- GSK3 $\beta$ eTF-2B is another pathway that stimulate protein synthesis in skeletal muscle hypertrophy.

\subsubsection{MAPK}

The MAPK pathway is an important pathway involved in IGF-I induced skeletal muscle hypertrophy. The detail of function of MAPK pathway in both myogenesis and mitogenesis has been mentioned before.

Compared to the PI3K pathway, the function of the MAPK pathway in skeletal muscle hypertrophy is less clear. An interaction between Raf-MEK-ERK pathway and PI3K-Akt pathway plays a role in the process of muscle hypertrophy [122;155;219]. PI3 kinase activity is essential for induction of Raf/MEK/ERK activity [177]. ERK1/2 pathway and PI3K pathway are both activated when upstream Ras is activated. Transfection of Ras can promote activation of PI3K as well as Raf-1, and a dominant negative Ras mutant inhibits growth factor induced activation of PI3K [153]. Activated Akt phosphorylates Raf at a highly conserved serine residue 
in its regulatory domain and inhibits activation of Raf/MEK/ERK signaling pathway [219]. The Akt-Raf interaction is dependent upon cellular context and dose of stimulus. Activation of Akt inhibits Raf activity in differentiated myotubes, but not in myoblast precursors [155]. High concentrations of IGF-I activates Akt strongly enough to inhibit Raf kinase activity, whereas low concentration of IGF-I retains mitogenic function that is insufficient to suppress Raf activity [122].

\subsubsection{Fibroblast Growth Factor 2 (FGF2)}

Among all the growth factors that regulate skeletal muscle hypertrophy, IGF-I, FGF2 and TGF- $\beta$ are the most extensively studied. There are more than 20 FGF family members, and FGF1, 2, 4, 5, 6, 8 and 10 are expressed in muscle.

FGF2 stimulates myoblast proliferation. Deletion of FGF2 signal through overexpression of a dominant negative FGF receptor 1 results in cell cycle withdrawal and suppression of myotube formation [53]. In vitro, FGF2 negatively regulates myogenesis. FGF2 blocks musclespecific gene expression and myotube fusion [55]. FGF2 localizes in the extracellular matrix of skeletal muscle fiber, and FGF2 accumulation augments muscle hypertrophy [205]. Inhibition of FGF receptor decreases muscle mass during embryonic development due to decreases in number of myoblasts, which suggests FGF2 is a positive regulator of muscle hypertrophy [53]. The possible mechanism for FGF2 stimulation of skeletal muscle hypertrophy may involve satellite cell activation and proliferation.

\subsubsection{Hepatocyte Growth Factor (HGF)}

Muscle satellite cells play a crucial role in muscle growth and injury repair. Normally satellite cells are in a quiescent state, until muscle growth or injury signals activate them. During the regeneration process, satellite cells proliferate, differentiate and express muscle specific proteins. Both in vivo and in vitro, HGF activates satellite cells [6]. HGF and its receptor, c-Met, 
are localized to satellite cells and adjacent myofibers, and their expression is induced by muscle injury [75]. HGF and c-Met are expressed in developing limb buds, and c-Met null mouse embryos fail to form limb skeletal muscle [15]. HGF promotes proliferation and inhibits differentiation of satellite cells, and fetal and adult myoblasts [61]. HGF inhibits by repressing $M y o D$ and myogenin transcription [61] HGF also causes the up regulation of twist, an inhibitor of differentiation and p27, a CDK inhibitor [103].

The actions of HGF are mediated by downstream induction of PI3K and ERK1/2 [102]. Grb2 is essential for phosphorylation of ERK1/2 and repression of myogenesis by HGF. Grb2 binds to PI3K in muscle cells and prompts elevated ERK1/2 activity [70].

\subsubsection{Growth Factors and Cytokines that Inhibit Muscle Hypertrophy}

\subsubsection{Transforming Growth Factor $\beta$ (TGF- $\beta$ )}

TGF- $\beta$ family is an important negative regulator of skeletal muscle hypertrophy. TGF- $\beta$ signals classically through Smad2 and Smad3 to disrupt all measures of muscle formation [108]. However, ERK1/2 phosphorylation can be induced by TGF- $\beta$ in some cell types [128]. The importance of ERK $1 / 2$ and TGF- $\beta$ signaling is underscored in myoblasts expressing constitutive Raf [193]. Strong sustained ERK $1 / 2$ signaling induces TGF- $\beta$ and GDF- 8 which may act as autocrine inhibitors of myogenesis.

TGF- $\beta$ inhibits myogenin-induced myogenesis in $10 \mathrm{~T} 1 / 2$ fibroblasts. TGF- $\beta$ treatment for 30 minutes reversibly induces MEF2 translocation to the cytoplasm of myogenic cells, which prevents MEF2 from participating in the transcriptional activation complex at muscle specific promoters [38]. Using truncated type II TGF- $\beta$ receptor as a dominant negative can inhibit myofiber formation and expression of MyoD, myogenin and other differentiation markers [52].

Growth and differentiation factor 8 (GDF-8, also called myostatin), a member of TGF-beta family, is expressed in embryonic and adult skeletal muscle. $G D F-8$ null mice are significantly 
larger than wild type animals with a $20-35 \%$ increase in muscle mass, which is result of both hyperplasia and hypertrophy [117]. Myostatin is a negative regulator of satellite cells. Myostatin inhibits myoblast proliferation through increasing $p 21$ expression and decrease $C d k 2$ expression leading to an accumulation of $\mathrm{Rb}$ protein, which in turn arrests myoblasts in $\mathrm{G} 1$ phase of cell cycle [176].

\subsubsection{Tumor Necrosis Factor-alpha (TNF- $\alpha)$}

TNF, IL-1 and IL-6 are inflammatory cytokines released by immune cells in response to foreign stimuli [187]. They are associated with the skeletal muscle catabolic response and have been shown to induce muscle wasting [187].

TNF- $\alpha$, also called cachectin, is expressed in diaphragm tissue, and anti-TNF- $\alpha$ antibody can prevent the deterioration of diaphragm muscle contractile properties [170]. TNF- $\alpha$ mediates skeletal muscle wasting through activation of NF-kB and AP-1 [192]. In C2C12 myoblasts, TNF induced NF-kB inhibits skeletal muscle differentiation by suppressing MyoD mRNA translation [68].

\subsubsection{Interleukin-6 (IL-6)}

IL-6 is a multifunctional cytokine that plays a major role in the inflammatory response and B-lymphocytes maturation [178]. Skeletal muscle produces IL-6, which is secreted into the plasma and increased during exercise [141]. IL-6 expression increases in myofibers after eccentric exercises, which indicates IL-6 may be related to muscle damage and regeneration caused by strenuous exercises [178]. Transgenic mice overexpressing IL-6 show muscle atrophy due to increased catheptic enzyme activity [181]. In addition, treatment with IL-6 receptor antibody can block the muscle atrophy and is effective against muscle wasting from sepsis and cancer cachexia [182]. 
The actions of IL-6 are mediated through STAT3 and ERK1/2 [4]. Human muscle cells treated with IL-6 demonstrate rapid phosphorylation of ERK1/2. LIF, a member of the IL-6 family, inhibits muscle gene transcript and myoblast fusion via MEK-dependent phosphorylation of ERK1/2 [81]. Thus, ERK1/2 signals may contribute to interleukin-mediated muscle atrophy.

\subsection{Summary of ERK1/2 Effects on Skeletal Myogenesis}

Muscle hypertrophy is promoted by IGF-I mediated signaling. IGF-I provokes two major intracellular signaling pathways; the ERK1/2 signaling cascade and the PI3K pathway. Initiation of ERK1/2 activity in response to IGF-I typically results in mitogenesis, although significant crosstalk exists between the ERK and PI3K systems. ERK1/2 activity inhibits myocyte formation independent of continued cell cycle progression. Importantly, the absolute levels of ERK1/2 signaling appear to affect myogenic decisions. Low-level ERK2 activity is associated with differentiation while sustained ERK1 and ERK2 activity is correlated with inhibition of myogenesis. Thus, signal transmission through ERK1/2 may have divergent effects on muscle form and function. 
Table 2-1. MRF null phenotypes

\begin{tabular}{|c|c|c|c|}
\hline Genotype & Viability & Phenotype & Reference \\
\hline MyoD[101] & Viable & $\begin{array}{l}\text { No obvious defects in skeletal muscle; with } \\
\text { increase myf5 expression }\end{array}$ & {$[19 ; 157]$} \\
\hline myf5[101] & $\begin{array}{l}\text { Perinatal } \\
\text { death }\end{array}$ & With normal muscle, defects in rib development & {$[20]$} \\
\hline myogenin[101] & $\begin{array}{l}\text { Perinatal } \\
\text { death }\end{array}$ & $\begin{array}{l}\text { Severe defects in differentiated muscle fiber, but } \\
\text { with normal numbers of myonuclei }\end{array}$ & {$[73 ; 129]$} \\
\hline MRF4[101] & viable & $\begin{array}{l}\text { Defective rib cage; high level of myogenin } \\
\text { expression }\end{array}$ & {$[139 ; 217]$} \\
\hline $\begin{array}{l}\text { MyoD }[101] \\
\text { myf5[101] }\end{array}$ & $\begin{array}{l}\text { Dead right } \\
\text { after borth }\end{array}$ & Complete absence of myoblasts and muscle fiber & [158] \\
\hline $\begin{array}{l}\text { myogenin[101] } \\
\text { MyoD/myf5 } \\
\text { /MRF4[101] }\end{array}$ & $\begin{array}{l}\text { Perinatal } \\
\text { death }\end{array}$ & Same phenotype as myogenin[101] mice & {$[148 ; 149]$} \\
\hline $\begin{array}{l}\text { myogenin[101] } \\
\text { MyoD[101] } \\
\text { MRF4[101] }\end{array}$ & $\begin{array}{l}\text { Perinatal } \\
\text { death }\end{array}$ & Same phenotype as myogenin[101] mice & {$[185]$} \\
\hline $\begin{array}{l}\text { MyoD }[101] \\
\text { MRF4[101] }\end{array}$ & $\begin{array}{l}\text { Perinatal } \\
\text { death }\end{array}$ & Same phenotype as myogenin[101] mice & [149] \\
\hline
\end{tabular}






Figure 2-1. MAPK signaling cascade 
Table 2-2. Summary of MAPK knockout mice phenotypes

\begin{tabular}{|c|c|c|c|}
\hline Genotype & Viability & Phenotype & Reference \\
\hline ERK1[101] & Viable & $\begin{array}{l}\text { Defects in thymocyte development, enhanced } \\
\text { long-term memory }\end{array}$ & {$[116 ; 137]$} \\
\hline ERK2[101] & $\begin{array}{l}\text { Embryonic } \\
\text { lethal }\end{array}$ & Defective in placenta development & [74] \\
\hline JNK1[101] & Viable & $\begin{array}{l}\text { Defective in } \mathrm{T} \text { cell activation and apoptosis of } \\
\text { thymocytes }\end{array}$ & {$[162]$} \\
\hline JNK2[101] & Viable & $\begin{array}{l}\text { Defective in } \mathrm{T} \text { cell activation and apoptosis of } \\
\text { thymocytes }\end{array}$ & {$[160]$} \\
\hline $\begin{array}{l}\text { JNK1[101] } \\
\text { JNK2[101] }\end{array}$ & $\begin{array}{l}\text { Embryonic } \\
\text { lethal }\end{array}$ & $\begin{array}{l}\text { Defective in neural tube closure, } \\
\text { UV-induced apoptosis }\end{array}$ & {$[94 ; 161 ; 180]$} \\
\hline JNK3[101] & Viable & $\begin{array}{l}\text { Defective in neuroprotection and stress-induced } \\
\text { neuronal apoptosis }\end{array}$ & [208] \\
\hline $\mathrm{p} 38 \alpha[101]$ & $\begin{array}{l}\text { Embryonic } \\
\text { lethal }\end{array}$ & Defective placental angiogenesis & {$[1 ; 127]$} \\
\hline $\begin{array}{l}\mathrm{p} 38 \beta[101] \\
\mathrm{p} 38 \gamma[101]\end{array}$ & Viable & No obvious phenotype & [95] \\
\hline ERK5[101] & $\begin{array}{l}\text { Embryonic } \\
\text { lethal }\end{array}$ & Defective blood vessel and myocardium & {$[150 ; 173 ; 206]$} \\
\hline
\end{tabular}


Table 2-3. Regulatory factors of skeletal muscle hypertrophy

\begin{tabular}{lll}
\hline Regulatory factors & Positive & Negative \\
\hline Exercise & $\begin{array}{l}\text { Strength training [48] } \\
\text { Resistance exercise [48] }\end{array}$ \\
Nutrition & Dietary protein supplement [48] & \\
Hormones & Testosterone [189] & Cortisol [79] \\
& Growth hormone [57] & \\
Growth factors & IGFs [114] & IL-1 [30] \\
& FGFs [205] & IL-6 [181] \\
& HGF [75] & TNF- $[154]$ \\
& & TGF- $\beta$ [220] \\
Others & Muscle satellite cells [75] & Muscle damage \\
& & Aging [48] \\
\hline
\end{tabular}




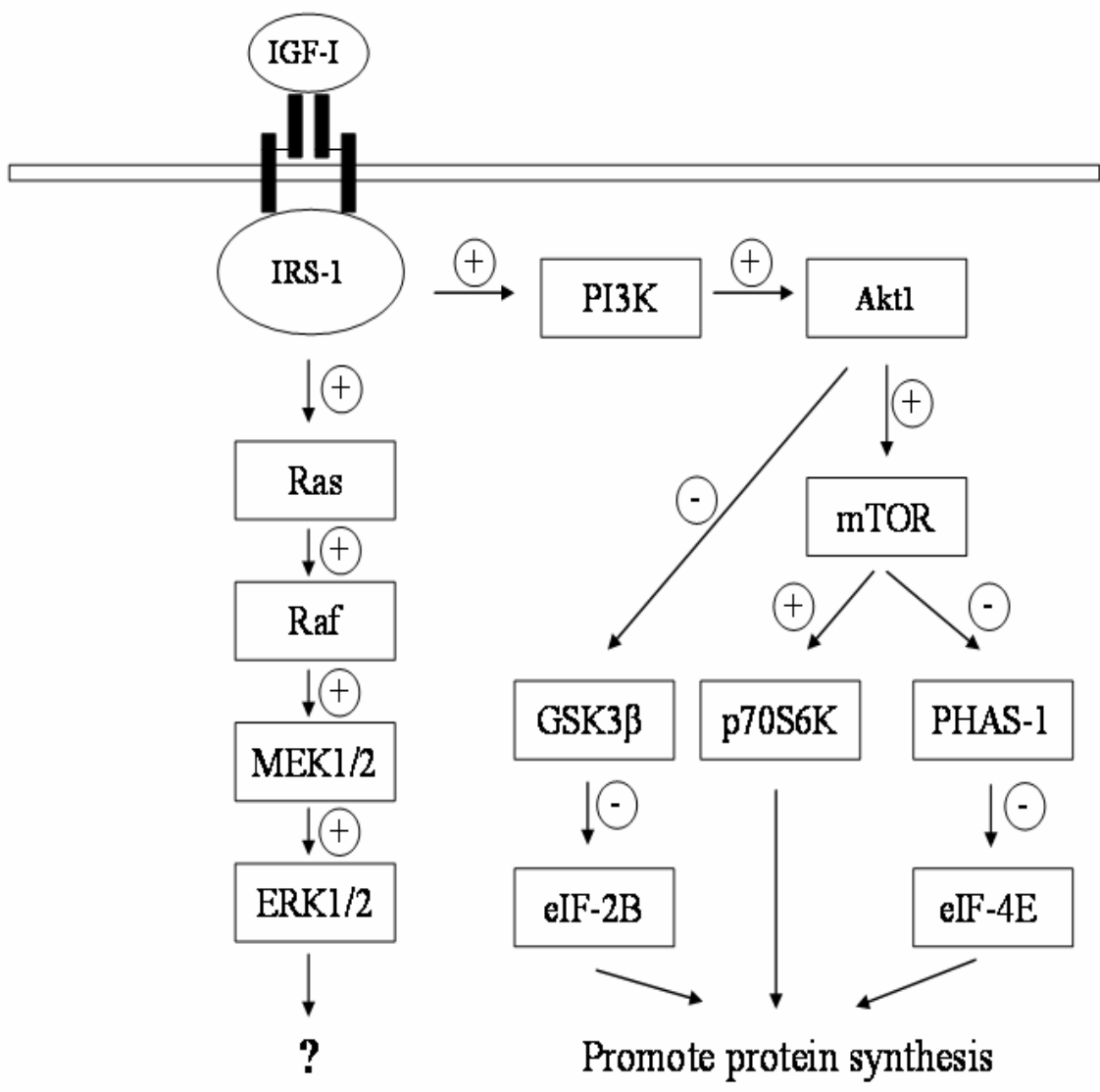

Figure 2-2. Signaling pathway involved in IGF-I induced skeletal muscle hypertrophy. 


\section{CHAPTER 3 \\ MATERIALS AND METHODS \\ 3.1 Cell Culture, Plasmids, and Transfection}

C2C12 myoblasts were cultivated on gelatin-coated tissue culture plasticware in high glucose Dulbecco's modified Eagle's medium supplemented with 15\% fetal bovine serum, 1\% penicillin-streptomycin, and 0.5\% gentamycin (Invitrogen, Carlsbad, CA). Differentiation was induced by culture in low glucose DMEM supplemented with $2 \%$ horse serum, $1 \%$ penicillinstreptomycin, and $0.5 \%$ gentamycin. Where appropriate, FGF2 was supplied at $5 \mathrm{ng} / \mathrm{mL}$ and IGFI was supplemented at $250 \mathrm{ng} / \mathrm{mL}$ levels (R\&D Systems, Minneapolis, MN). Inhibition of MEK1/2 activity was accomplished by supplementation of culture medium with $25 \mu \mathrm{M}$ PD98059 (Cell Signaling, Beverly, MA).

\subsection{RNA Interference}

Small interfering RNAs were constructed using an artificial neural network [76]. The double-stranded oligonucleotides coding for siRNA directed against mouse ERK1 mRNA were 5'-AATGTTATAGGCATCCGAGAC, targeting a region spanning 312-333 and 5'AAGCCTTCCAATCTGCTTATC, targeting the region spanning 519-540. Oligonucleotide sequences of the DNA coding for siRNA against ERK2 were 5'-

AAAGTTCGAGTTGCTATCAAG and 5'-AAGAGGATTGAAGTTGAACAG, complimentary to nucleotide sequences 355-376 and 1111-1132 of mouse ERK2 mRNA. The double-stranded DNAs were cloned first in to RNAi-Ready pSIREN-RetroQ-ZsGreen Retroviral Vector (BD Biosciences Clontech). Single pSIREN-RetroQ-ZsGreen plasmid coding for ERK1 or ERK2 siRNA was transfected into PT67 packaging cell line by calcium phosphate precipitation [82]. The growth medium with virus was collecting between 24 hours and 72 hours after transfection. Add polybrene to the medium to a final concentration of $4 \mu \mathrm{g} / \mathrm{mL}$ and then filter the medium 
through $0.45 \mu \mathrm{m}$ filter. Then the retrovirus was used to infected $\mathrm{C} 2 \mathrm{C} 12$ myoblasts for 48 hours. The double-strand nucleotides were also cloned into the pSilencer vector (Ambion, Woodlands, TX). Single or pairs of pSilencer plasmids coding for ERK1 or ERK2 siRNAs were transiently transfected into $\mathrm{C} 2 \mathrm{C} 12$ myoblasts by calcium phosphate precipitate formation. The myoblasts were selected in growth medium containing $400 \mu \mathrm{g} / \mathrm{mL}$ G418 (Invitrogen, Carlsbad, CA) for 10 days to create the stable cell lines, C2C12siERK1 and C2C12siERK2. C2C12siCon myoblasts stably express pSilencer containing a randomized 21 base pair cDNA insert.

\subsection{Luciferase Reporter Assay}

C2C12siCon, C2C12siERK1, and C2C12siERK2 myoblasts $(1 \times 105)$ were cotransfected with $1 \mu \mathrm{g}$ of a multimerized AP1 DNA binding site driving expression of luciferase (AP1-Luc), $50 \mathrm{ng}$ pRLtk, a Renilla luciferase expression plasmid as an efficiency monitor, and $0.5 \mu \mathrm{g}$ of pCS2 + MT or pCS2 + MT-RafBXB [82]. After $48 \mathrm{~h}$ in growth medium, the cells were lysed and luciferase activities measured (Dual-Luciferase Reporter kit, Promega, Madison, WI). Transfection efficiency was normalized by pRLtk activity. The assay was repeated three times.

\subsection{BrdU Incorporation}

A BrdU incorporation assay was performed to measure DNA synthesis. C2C12siCon, C2C12siERK1, and C2C12siERK2 myofibers were incubated with fresh medium containing 10 $\mu \mathrm{M}$ BrdU for $30 \mathrm{~min}$, and then BrdU immunocytochemistry staining and label index counting were performed. The BrdU labeling index was assessed by point counting a total of 400 to 1000 nuclei in 6-8 representative fields. The labeling index was counted as the number of positively labeled nuclei divided by total number of nuclei times $100 \%$. 


\subsection{Western Blot}

C2C12siCon, C2C12siERK1, and C2C12siERK2 myofibers were lysed in 4× sample buffer (250 mM Tris, pH 6.8, 8\% SDS, 40\% glycerol, and 0.4\% $\beta$-mercaptoethanol) and heated at $95{ }^{\circ} \mathrm{C}$ for $5 \mathrm{~min}$. Proteins were separated through $10 \%$ polyacrylamide gels under denaturing conditions and transferred to nitrocellulose membrane. The membranes were incubated with 5\% nonfat dried milk in TBST (10 mM Tris, $\mathrm{pH} 8.0,150 \mathrm{mM} \mathrm{NaCl}$, and $0.1 \%$ Tween 20$)$ to block non-specific binding sites. Blots were incubated overnight at $4{ }^{\circ} \mathrm{C}$ with anti-ERK $1 / 2$, antiphosphoERK1/2, anti-Akt or anti-phosphoAkt (Cell Signaling, Danvers, MA) or for $1 \mathrm{~h}$ at room temperature with anti-myosin heavy chain (MF20), anti-myogenin (F5D), anti-desmin (D3,Developmental Studies Hybridoma Bank, University of Iowa, Ames, IA) or anti-troponin T [188]. After extensive washes with TBST, the blots were incubated with appropriate peroxidaseconjugated secondary antibody for $1 \mathrm{~h}$, following by chemiluminescent detection (ECL, Amersham, Piscataway, NJ) and exposure to X-ray film.

\subsection{Immunocytochemistry}

C2C12siERK1, C2C12siERK2, and C2C12siCon cells were fixed with 4\% paraformaldehyde in phosphate-buffered saline (PBS) for $10 \mathrm{~min}$ at room temperature. Nonspecific antigen sites were blocked with PBS containing 5\% horse serum and $0.1 \%$ Tween 20 . Cultures were incubated with anti-myosin heavy chain (MF20, 1:10 hybridoma supernatant) for 1 h. After exhaustive rinses with PBS, the fixed cultures were incubated with donkey antimouse-AlexaFluor488 antibodies. Cultures were counterstained with Hoescht 33325 for the visualization of nuclei. Immunofluorescence was detected with a Nikon TE2000 inverted phase microscope equipped with epifluorescence. Representative images were captured with a DMF1200 digital camera and compiled with Lucia Imaging software. For the detection of BrdU incorporation, myoblasts were fixed with $70 \%$ ethanol for $1 \mathrm{~h}$ at $4{ }^{\circ} \mathrm{C}$. DNA was denatured with 
$2 \mathrm{~N} \mathrm{HCl}$ for $1 \mathrm{~h}$ in $37^{\circ} \mathrm{C}$. Fixed cultures were neutralized and incubated with anti-BrdU (1:50, Invitrogen-Molecular Probes, Carlsbad, CA) for $1 \mathrm{~h}$ at room temperature. Subsequently, cells were incubated with goat anti-mouse-biotin and streptavidin-peroxidase (ABC kit, Vector Labs, Burlingame, CA). Labeled nuclei were visualized colorimetrically using 3,3'-diaminobenzidine and nickel chloride. 


\section{CHAPTER 4}

RESULTS

\subsection{Preliminary Experiment}

To test the discrete functions of ERK1 and ERK2, a cDNA coding for one siRNA for each ERK isoform was synthesized and cloned into RNAi-Ready pSIREN-RetroQ-ZsGreen Retroviral Vector. This vector contains a cDNA coding for Green Fluorescence Protein (GFP) that allows for identification of transduced cells. pSIRENsiERK1 or pSIRENsiERK2 were transfected into the packaging cell line PT67, and replication defective retrovirus were harvested. $\mathrm{C} 2 \mathrm{C} 12$ myoblasts were transduced with the retrovirus and infection efficiency was monitored by fluorescent GFP detection. Results indicate less than $10 \%$ of $\mathrm{C} 2 \mathrm{C} 12$ myoblasts were infected (Figure 4-1). To evaluate siRNA knockdown, total cellular protein lysates were prepared from C2C12 infected by ERK1 or ERK2 siRNA and uninfected control C2C12 myoblasts, and analyzed by Western blot for ERK1 and ERK2 proteins (Figure 4-2). The C2C12 myoblasts infected with ERK1 or ERK2 siRNA had no significant reduction in ERK1 and ERK2 protein by comparison with control cells. Due to low infection rates and poor knockdown of ERK1 and ERK2, this method was discontinued.

To increase the proportion of cells incorporating ERK1 or ERK2 siRNA, two stable myogenic cell lines constitutively expressing a single siRNA were synthesized. siRNAs were cloned into pSilencer vector and selected for neomyosin resistance after tranfection of $\mathrm{C} 2 \mathrm{C} 12$ myoblasts. The protein expression level was analyzed by Western blot for ERK1/2 and $\alpha$-tubulin. Compared to control cells, C2C12 with single siRNA of ERK1 or ERK2 had no reduction in ERK kinase expression (Figure 4-3). 


\subsection{Creation and Validation of ERK1 and ERK2 siRNA}

Stable myogenic cell lines incorporating a single siRNA is inefficient, therefore, two siRNAs for each target kinase were synthesized using an artificial neural network program [76]. C2C12 myoblasts were transfected with plasmids coding for the ERK siRNAs followed by selection for neomycin resistance. To evaluate the level of message knockdown, total cellular protein lysates were prepared from $\mathrm{C} 2 \mathrm{C} 12 \mathrm{siCon}, \mathrm{C} 2 \mathrm{C} 12 \mathrm{siERK} 1$, and $\mathrm{C} 2 \mathrm{C} 12 \mathrm{siERK} 2$, and analyzed by Western for ERK1/2 protein expression (Figure 4-4A). Control myoblasts readily synthesize the two kinases. C2C12siERK1 and C2C12siERK2 both produce severely reduced amounts of the ERK proteins. The siRNAs are specific for the targets of interest as no alterations in protein size or concentration of the reciprocal kinases were observed. Residual kinase activity was measured by Western using an antibody against phospho-ERK1/2. C2C12siERK1 contained a higher relative amount of phosphoERK2 than controls (C2C12siCon). C2C12siERK2 contained a severe reduction in both total and phosphoERK2. To quantify the reduction of the various forms of ERK1/2, replicate blots were analyzed by scanning densitometry. Results indicate that ERK1 protein expression is $80 \%$ lower than the amount synthesized by control myoblasts (Figure 4-4B). ERK2 and phosphoERK2 proteins are reduced $85 \%$ by comparison to controls. To verify that loss of ERK1/2 causes a biological response, C2C12siCon, C2C12siERK1, and C2C12siERK2 myoblasts were transfected with plasmids coding for activated Raf and an AP1-Luc reporter. As shown in Figure 4-5, C2C12siCon myoblasts contain ERK1/2 proteins that promote the efficient transcription from AP1-Luc. A reduction in ERK1 or ERK2 protein results in a decrease in Raf/ERK directed reporter gene expression.

\subsection{Optimal Myoblast Proliferation Requires One Functional ERK Enzyme}

ERK1/2 are involved in mitosis and cell proliferation [140]. Inhibition of their activation leads to growth arrest in many cells including myoblasts [83]. The necessity for each ERK 
during myoblast proliferation was measured in $\mathrm{C} 2 \mathrm{C} 12$ siCon, $\mathrm{C} 2 \mathrm{C} 12$ siERK1, and $\mathrm{C} 2 \mathrm{C} 12$ siERK2 myoblasts. Equal numbers of myoblasts were cultured for 4 days in mitogen poor medium. Cell numbers were measured daily. A representative growth curve is shown in Figure 4-6. Knockdown of ERK1 mRNA did not elicit an effect on myoblast proliferation. C2C12siCon and C2C12siERK1 expanded at comparable rates. Myoblasts synthesizing reduced levels of ERK2 tend to grow slower than either controls or siERK1 myoblasts, although this is not statistically significant. To confirm variable growth rates, the myoblast populations were cultured for $48 \mathrm{~h}$ under similar conditions and pulse labeled with BrdU for 30 min prior to fixation. Results indicate that $34 \%, 34 \%$, and $28 \%$ of the cells are present in S-phase for cultures of $\mathrm{C} 2 \mathrm{C} 12 \mathrm{siCon}$, C2C12siERK1, and C2C12siERK2, respectively, (Figure 4-7). The reduction in BrdU incorporation supports a tendency toward depressed growth rates of ERK2 deficient myoblasts. To determine if both ERK proteins are necessary for the mitogenic response to FGF2 or IGF-I, cultures of $\mathrm{C} 2 \mathrm{C} 12$ siCon, $\mathrm{C} 2 \mathrm{C} 12 \mathrm{siERK} 1$, and $\mathrm{C} 2 \mathrm{C} 12 \mathrm{siERK} 2$ were treated for $48 \mathrm{~h}$ with the growth factors. BrdU incorporation was measured during the final 30 min of treatment. Treatment of control myoblasts with $5 \mathrm{ng} / \mathrm{mL}$ FGF2 causes a 2-fold increase in the numbers of actively dividing cells (Figure 4-7). A similar response was found in C2C12siERK1 myoblasts treated with the mitogen. The increased cell division was somewhat tempered in C2C12siERK2 myoblasts treated with FGF2, though not significant. In a similar manner, C2C12siCon, $\mathrm{C} 2 \mathrm{C} 12$ siERK1, and $\mathrm{C} 2 \mathrm{C} 12$ siERK2 myoblasts proliferate in response to IGF-I treatment. Thus, efficient myoblast proliferation necessitates a single functional ERK allele.

\subsection{ERK2 is Necessary for Efficient Myofiber Formation}

The effects of differential ERK1 and ERK2 function on myofiber formation and muscle gene expression were examined in $\mathrm{C} 2 \mathrm{C} 12$ myoblasts. $\mathrm{C} 2 \mathrm{C} 12$ siCon, $\mathrm{C} 2 \mathrm{C} 12 \mathrm{siERK} 1$, and C2C12siERK2 myoblasts were induced to differentiate by culture in 2\% horse serum for $48 \mathrm{~h}$. 
Cultures were fixed and immunostained for myosin heavy chain (MyHC), a marker of terminal differentiation. The scrambled siRNA did not interfere with the ability of $\mathrm{C} 2 \mathrm{C} 12$ myoblasts to differentiate (Figure 4-8). Large multinucleated myofibers were apparent that readily expressed the contractile protein. A similar result was evident in cultures of C2C12siERK1 cells. By contrast, C2C12siERK2 myoblasts failed to fuse into large syncitia. A portion of the myoblasts expressed MyHC but these cells were mononucleated with a spindle- like morphology. A differentiation index was calculated as the numbers of nuclei in MyHC expressing myofibers divided by the total number of nuclei. By comparison to control and C2C12siERK1 cells, C2C12siERK2 myoblasts formed 50\% fewer myosin-expressing cells (Figure 4-9). Coincident with the reduced differentiation capabilities is a severe impairment in myoblast fusion. A fusion index was calculated as the number of MyHC immunopositive fibers with two or more nuclei divided by the total number of nuclei. C2C12siERK2 myoblasts possess fewer than 5\% multinucleated MyHC expressing fibers. These results argue that ERK2 signaling is needed for optimal differentiation and myoblast fusion. Alternatively, myofiber formation may require elimination of an ERK1 signal. To clarify the role of ERK2 as a positive effector of myogenesis, confluent cultures of $\mathrm{C} 2 \mathrm{C} 12$ siERK2 myoblasts were treated with $25 \mu \mathrm{M}$ PD98059 under differentiation-permissive conditions. The concentration of PD98059 is sufficient to inhibit the phosphorylation of ERK1 (Figure 4-10). After $48 \mathrm{~h}$, the cells were fixed and immunostained for MyHC expression. As shown in Figure 4-11, no increase in the numbers or size of MyHC expressing myofibers is apparent. Because inhibition of ERK1 function does not restore the myogenic program, ERK2 must play an essential role during myogenesis.

\subsection{ERK2 Knockdown Inhibits Myogenin Protein Expression}

Myogenin expression is a requisite for efficient myofibers formation and muscle gene expression [73]. The reduction in fiber number and contractile protein expression suggested that 
myogenin expression was compromised. Therefore, equal amounts of protein were analyzed by Western blot using antibodies specific for myogenin and a-tubulin (Figure 4-12). C2C12siERK2 myoblasts synthesize significantly less myogenin protein. To determine if restoration of myogenin protein expression can alleviate the block to optimal muscle formation in ERK2 deficient myoblasts, the cells were treated with IGF-I [183]. In brief, C2C12siERK2 myoblasts were grown for $48 \mathrm{~h}$ in differentiation medium supplemented with $250 \mathrm{ng} / \mathrm{mL}$ IGF-I. Total cellular lysates were isolated and analyzed for myogenin protein expression. IGF-I supplementation increased relative myogenin protein levels in C2C12siERK2 myoblasts to levels comparable to untreated $\mathrm{C} 2 \mathrm{C} 12$ siCon myoblasts. The amount of myogenin protein was quantified and corrected for a-tubulin expression. As shown in Figure 4-13, C2C12siERK2 myoblasts synthesize myogenin at concentrations less than $60 \%$ of wildtype. Treatment of C2C12siCon, C2C12siERK1, and C2C12siERK2 myoblasts with IGF-I increased the amount of myogenin protein, as expected [183].

\subsection{IGF-I Signaling Partially Restores Myogenin Expression and Myofiber Formation}

To determine if increased myogenin expression can restore differentiation and fusion to ERK2 deficient myoblasts, C2C12siCon, C2C12siERK1, and C2C12siERK2 myoblasts were cultured with IGF-I for $48 \mathrm{~h}$ prior to fixation and assessment of differentiation. Immunocytochemical staining for MyHC in IGF-I treated C2C12siERK2 myoblasts noted the appearance of larger myofibers containing three or more nuclei (Figure 4-14). Approximately $10 \%$ of the total nuclei were present in MyHC immunopositive myofibers that contained two or more nuclei (Figure 4-15). Interestingly, C2C12siERK1 myoblasts contain no detectable ERK1 protein and are more responsive to IGF-I treatment. The numbers of nuclei found in myofibers doubles in C2C12siERK1 cultures receiving ectopic IGF-I. Treatment with IGF-I for $48 \mathrm{~h}$ did not significantly increase the total number of nuclei (one or more) contained within myosin 
expressing cells (Figure 4-16). These results suggest that ERK2 is necessary for myogenin expression, which promotes myoblast fusion.

A major intracellular signaling cascade invoked by IGF-I involves the sequential activation of PI3-kinase and Akt [80;105]. Inhibition of PI3-kinase signaling leads to a complete loss of myofiber formation in avian and rodent myoblasts $[80 ; 85 ; 144]$ To ensure that the preferred IGF-I signaling system is intact in the ERK deficient myoblasts, confluent cultures of C2C12siCon, C2C12siERK1, and C2C12siERK2 myoblasts were treated with IGF-I for $48 \mathrm{~h}$. Total cellular lysates were prepared and analyzed by Western for Akt and phosphoAkt (Figure 4-17). As predicted, IGF-I treatment caused a significant increase in the amounts of active Akt in all instances. Thus, the inability of IGF-I to more fully restore the differentiation program to ERK2 deficient myoblasts is not due to a faulty PI3 kinase-mediated intracellular signaling system.

\subsection{FGF2 Does Not Signal Exclusively through Either ERK1 or ERK2 to Inhibit Myogenesis}

FGF2 is an extremely potent antagonist to muscle formation in vitro [134]. The growth factor stimulates ERK1/2 phosphorylation in C2C12 myoblasts and inhibition of ERK1/2 function leads to an increase in myogenin and MyHC protein expression [120]. Becaue C2C12siERK1 myoblasts readily form large myofibers; we examined the possibility that biased ERK2 function could deter the inhibitory actions of FGF2 on myogenesis. To this end, C2C12siCon, C2C12siERK1, and C2C12siERK2 myoblasts were induced to differentiate in the presence or absence of $5 \mathrm{ng} / \mathrm{mL}$ FGF2. Myoblast cultures were fixed and immunostained for MyHC expression and a differentiation index was constructed. Parallel cultures were lysed for Western blot analysis. As shown in Figure 4-18, treatment with FGF2 effectively eliminated myofiber formation in all myoblast cell types. Fewer than $5 \%$ of the $\mathrm{C} 2 \mathrm{C} 12$ siCon, 
C2C12siERK1 or C2C12siERK2 myoblasts fused into multinucleate fibers (Figure 4-19). Western blot analysis using anti-MyHC and anti-myogenin revealed that neither of the aforementioned proteins is synthesized in FGF2 treated myoblasts (Figure 4-20). Thus, all measures of morphological and biochemical differentiation are ablated by FGF2 treatment of wildtype, ERK1 or ERK2 deficient myoblasts. Previous reports indicate that inhibition of the upstream kinase, MEK1/2, reverses the suppression actions of FGF2 [120;179]. A similar result is found in the ERK1 and ERK2 deficient myoblasts (Figure 4-20). Treatment with $25 \mu \mathrm{M}$ PD98059, a concentration that prevents efficient phosphorylation of ERK1/2 resulted in an increase in muscle protein expression. However, myogenic protein levels remained lower than those found in nontreated controls. 


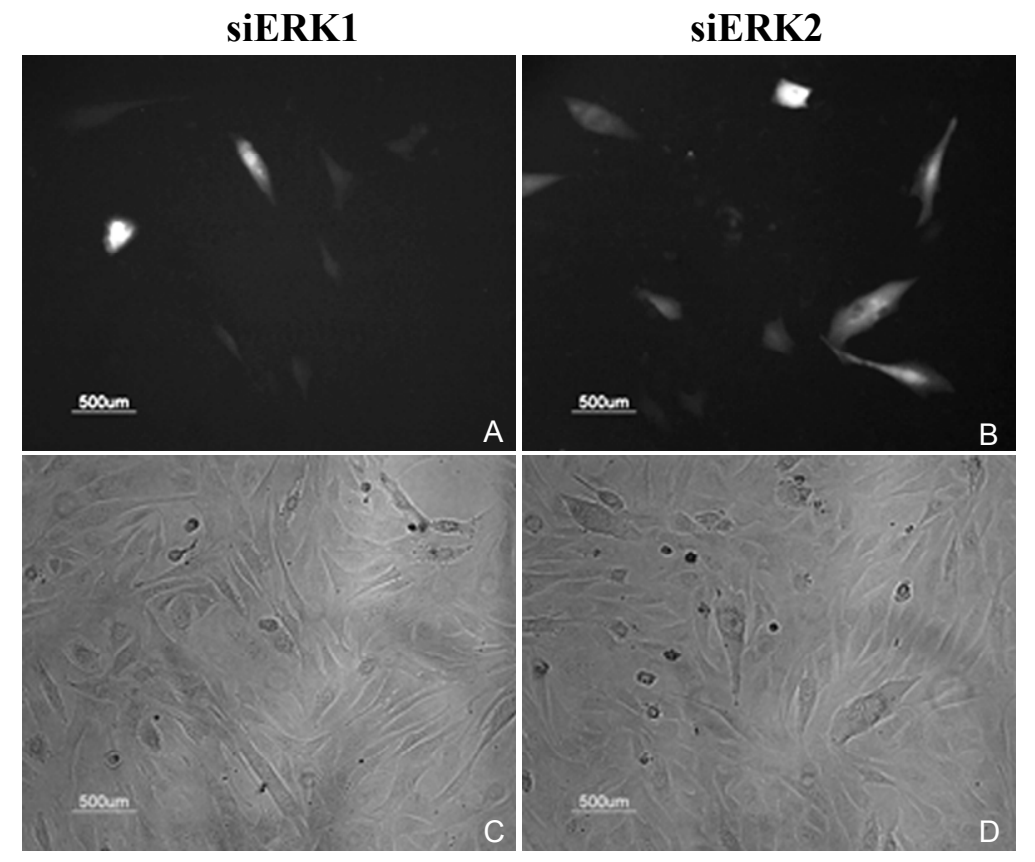

Figure 4-1. C2C12 myoblasts transduced with pSIRENsiERK1 and pSIRENsiERK2. C2C12 myoblasts were infected with retrovirus containing single siRNA specific against ERK1 and ERK2. Cells were cultured in growth medium for $48 \mathrm{~h}$. Representation phase as 200x showing GFP transduced cells (A, B) and corresponding phase contrast microscopic field $(C, D)$. 


\section{SIERK1 siERK2 Control}

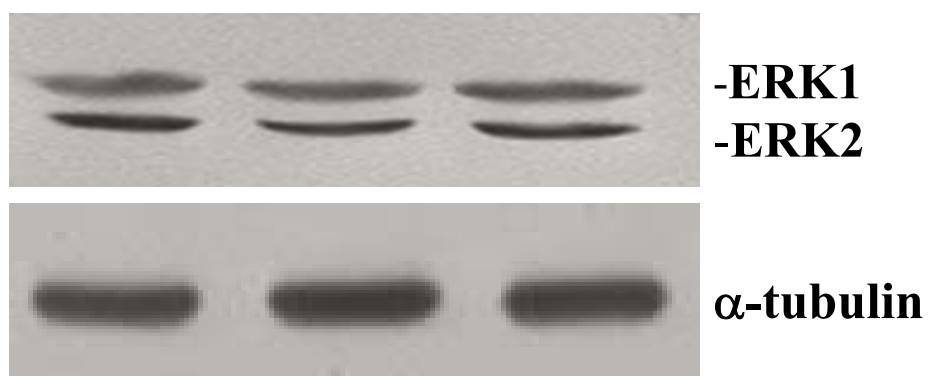

Figure 4-2. C2C12 myoblasts transduced with pSIRENsiERK1 or pSIRENsiERK2 does not inhibit ERK1/2 expression. C2C12 myoblasts were infected with retrovirus containing single siRNA specific against ERK1, ERK2 or scambled control oligonucleotide. Cells were cultured in growth medium for $24 \mathrm{~h}$. Then total protein isolates were harvested and analyzed by Western blot for total ERK1 and ERK2 protein, or tubulin protein expression. 


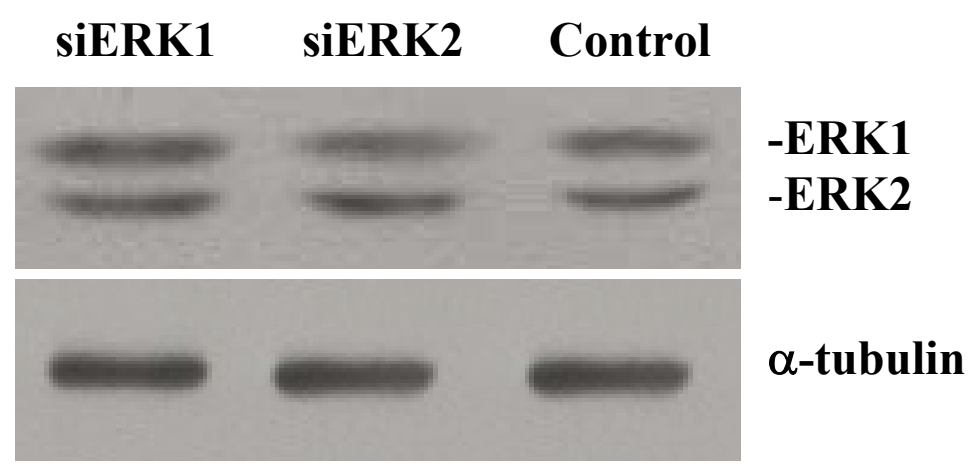

Figure 4-3. C2C12 myoblasts stable expressing single siERK1 or siERK2 does not inhibit ERK1/2 expressio. C2C12 myoblasts were transfected with single siRNA specific against ERK1, ERK2 or scambled control oligonucleotide. Cells were cultured in growth medium for $24 \mathrm{~h}$. Then total protein isolates were harvested and analyzed by Western blot for total ERK1 and ERK2 protein, or tubulin protein expression. 
A

C2C12



B



Figure 4-4. Stable expression of siRNA directed against ERK1 or ERK2 reduces ERK1/2 protein levels. A) C2C12 myoblasts were selected for stable expression of a siRNA against ERK1, ERK2 or scambled control oligonucleotide. Total protein isolates were harvested and analyzed by Western blot for total ERK1 and ERK2 protein, active ERK1/2 or tubulin protein expression. B) Scanning densitometry was used to qualify the reduction in protein production. Data represent means and standard errors for three impendent experiments. 




Figure 4-5. Knockdown of ERK1 or ERK2 affects AP1 luciferase activity. C2C12siCon, C2C12 siERK1 and C2C12siERK2 myoblasts were transiently transfected with AP1-Luc, pRLtk, and pCS2+MT or pCS2+MT-RafBXB. Luciferase activities were measures after $48 \mathrm{~h}$ in culture. Relative AP1-Luc was calculated as AP1-Luc/pRLtk. Data represent means and standard errors for three impendent experiments. 


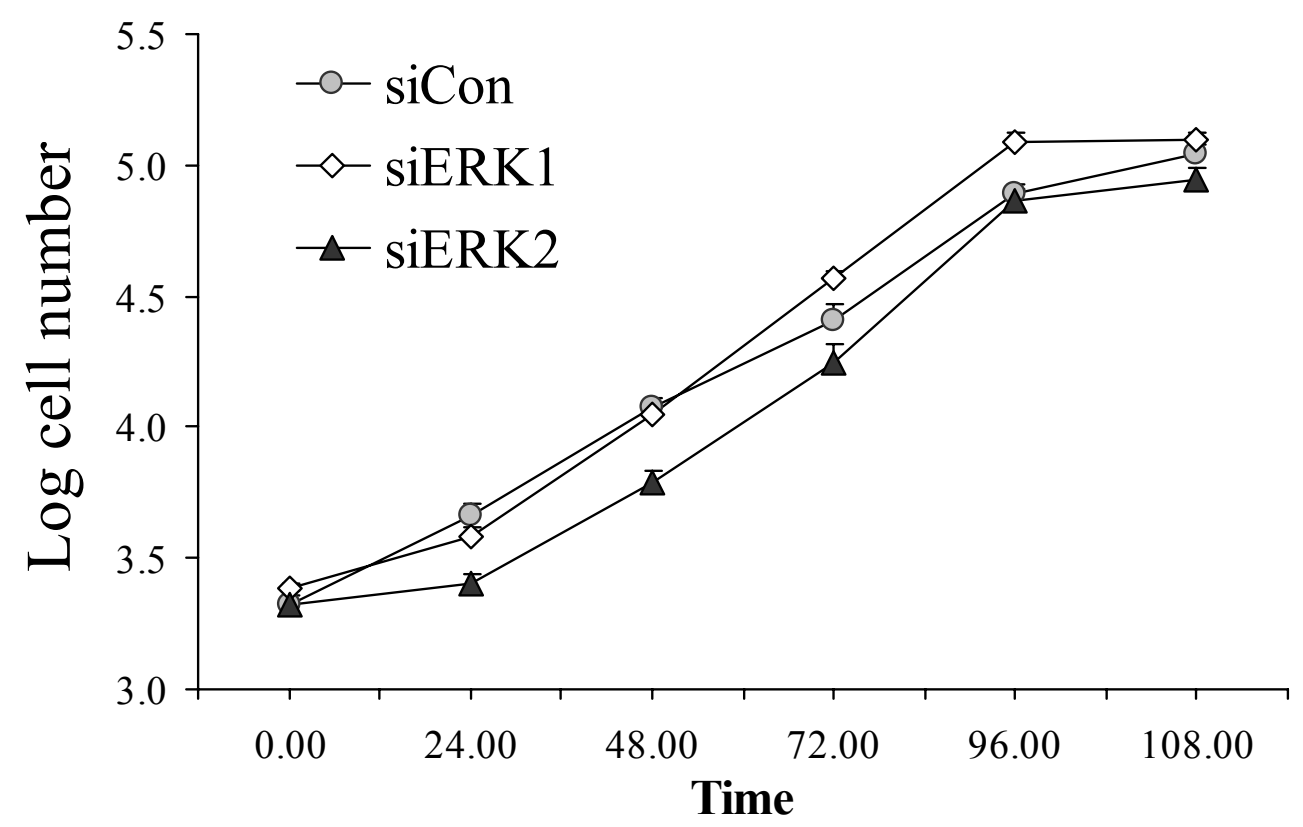

Figure 4-6. Knockdown of ERK1 or ERK2 does not prevent myoblast proliferation. C2C12siCon, C2C12siERK1 and C2C12siERK2 myoblasts were seeded at equal density and cultures in reduced serum medium for 5 days, cell numbers were measured daily. 




Figure 4-7. Knockdown of ERK1 or ERK2 does not affect the mitogenic response. C2C12siCon, C2C12siERK1 and C2C12siERK2 myoblasts were cultured as described for $48 \mathrm{~h}$ in the presence or absence of $5 \mathrm{ng} / \mathrm{mL}$ FGF2 or $250 \mathrm{ng} / \mathrm{mL}$ IGF-I. Thirty minutes prior to fixation, cekks were pulsed with BrdU. Immunopositive BrdU nuclei and total nuclei were counted. Mitotic index was calculated as $[\mathrm{BrdU}(+) /$ total $] * 100$. Means and standard errors of three independent experiments are shown. 


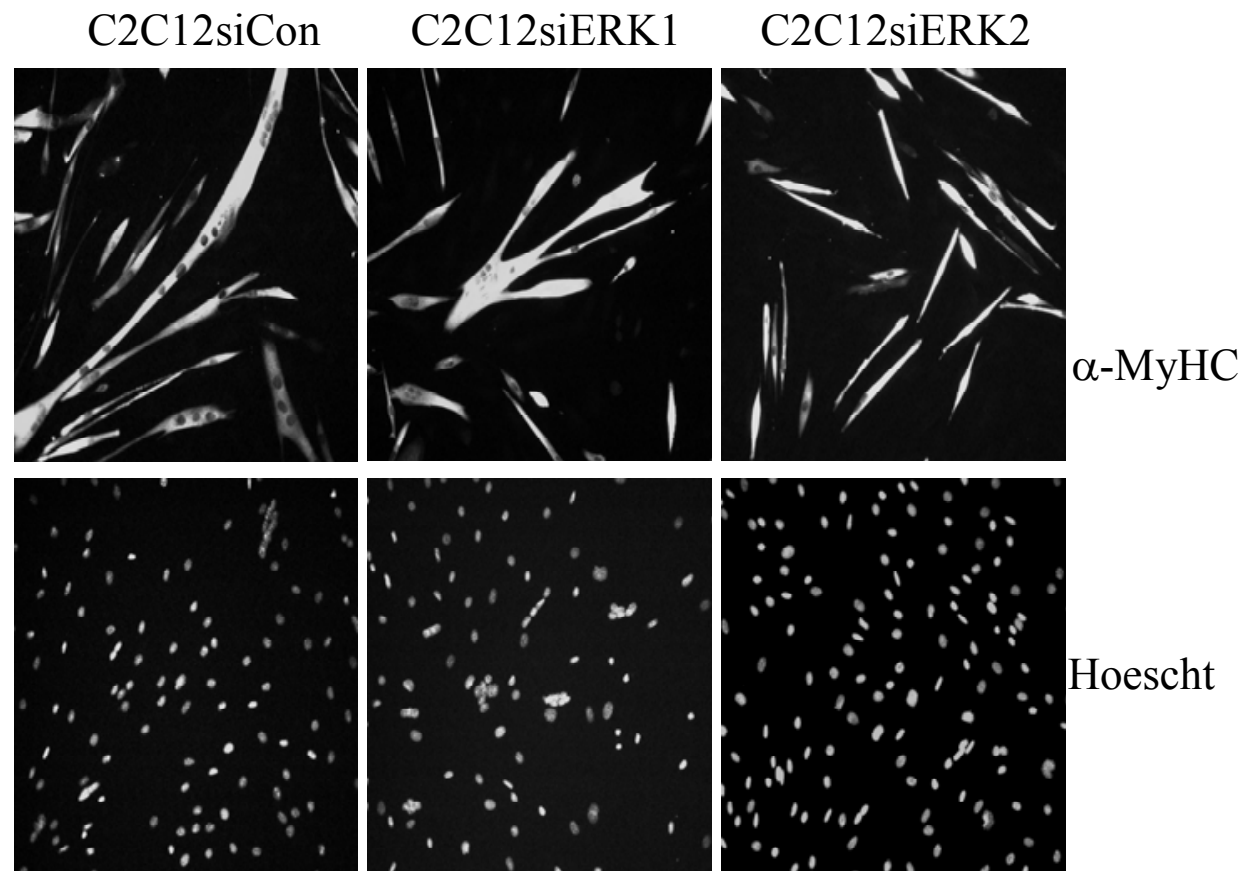

Figure 4-8. ERK2 deficiency leads to myogenic arrest. C2C12siCon, C2C12siERK1 and C2C12siERK2 myoblasts were cultured in differentiation-permissive medium for 48 $\mathrm{h}$ prior to fixation and immunostaining for myosin heavy chain. Total nuclei were visualized by Hoechst stain. 




Figure 4-9. ERK2 deficiency leads to repression of differentiation and fusion of myoblasts. C2C12siCon, C2C12siERK1 and C2C12siERK2 myoblasts were cultured in differentiation-permissive medium for $48 \mathrm{~h}$ prior to fixation and immunostaining for myosin heavy chain. Total nuclei were visualized by Hoechst stain. A differentiation index was calculated as the number of nuclei in $\mathrm{MyHC}(+)$ fibers/total nuclei*100. A fusion index was calculated as the number of fibers containing a minimum of two nuclei divided by total nuclei. 


\section{C2C12 siERK2}


\section{ERK1}

ERK2



pERK1

pERK2

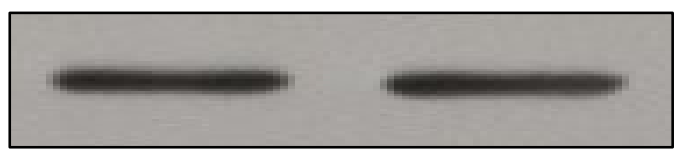

\section{$\alpha$-tubulin}

Figure 4-10. Treatment with PD98059 inhibits activation of ERK1/2 and active ERK1/2.

C2C12siERK2 myoblasts were differentiated for $48 \mathrm{~h}$ in the presence or absence of $25 \mu \mathrm{M}$ PD98059. Cultures were lysed lysed and equal amounts of protein were analysed by Western for total ERK1/2 protein, active ERK1/2 protein or tubulin protein expression. 

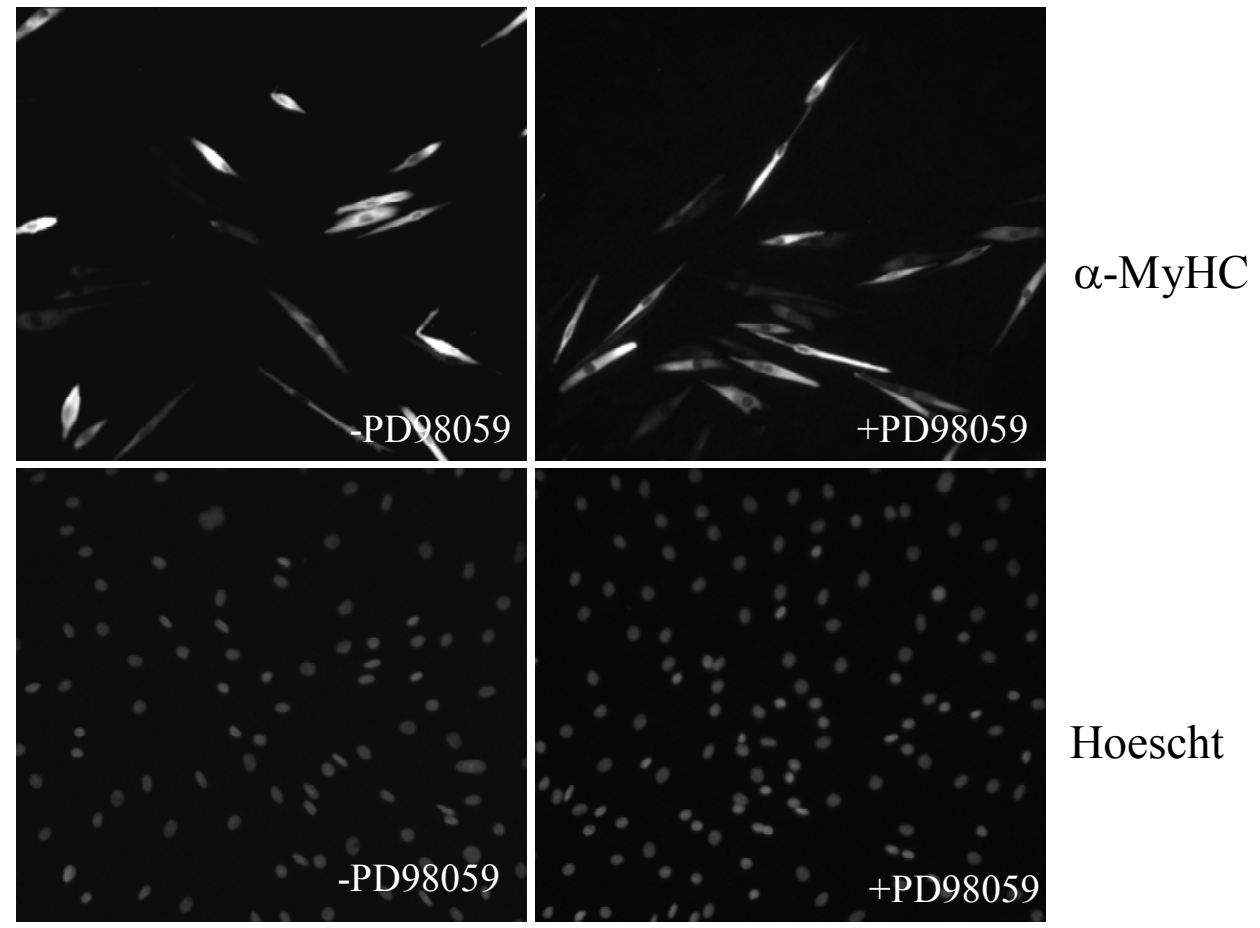

Figure 4-11. Treatment with PD98059 does not affect C2C12siERK2 differentiation.

C2C12siERK2 myoblasts were differentiated for $48 \mathrm{~h}$ in the presence or absence of $25 \mu \mathrm{M}$ PD98059. Myoblasts were fixed and immunostained for MyHC. Total nuclei were visualized by Hoechst stain. 




Figure 4-12. ERK2 deficiency causes a reduction in myogenin protein expression. C2C12siCon, C2C12siERK1 and C2C12siERK2 myoblasts were maintained in differentiation medium for $48 \mathrm{~h}$. Cultures were lysed and equal amounts of protein were analyzed by Western for myosin heavy chain, myogenin, troponin, desmin and tubulin. 
A



$\mathrm{B}$



Figure 4-13. ERK2 deficiency causes reducted myogenin expression in C2C12siERK2 myoblasts is partially restored by IGF-I treatment. C2C12siCon, C2C12siERK1 and C2C12siERK2 myoblasts were maintained in differentiation medium for $48 \mathrm{~h}$ in presence or absence of $250 \mathrm{ng} / \mathrm{mL}$ IGF-I. Cultures were lysed and equal amounts of protein were analyzed by Western for myogenin, desmin and tubulin (A). The relative amounts of myogenin protein were measured by scanning densitometry and ImageQuant software analysis. Myogenin content was normalized to $\alpha$-tubulin (B). Results are means and standard errors of three independent analyses. 


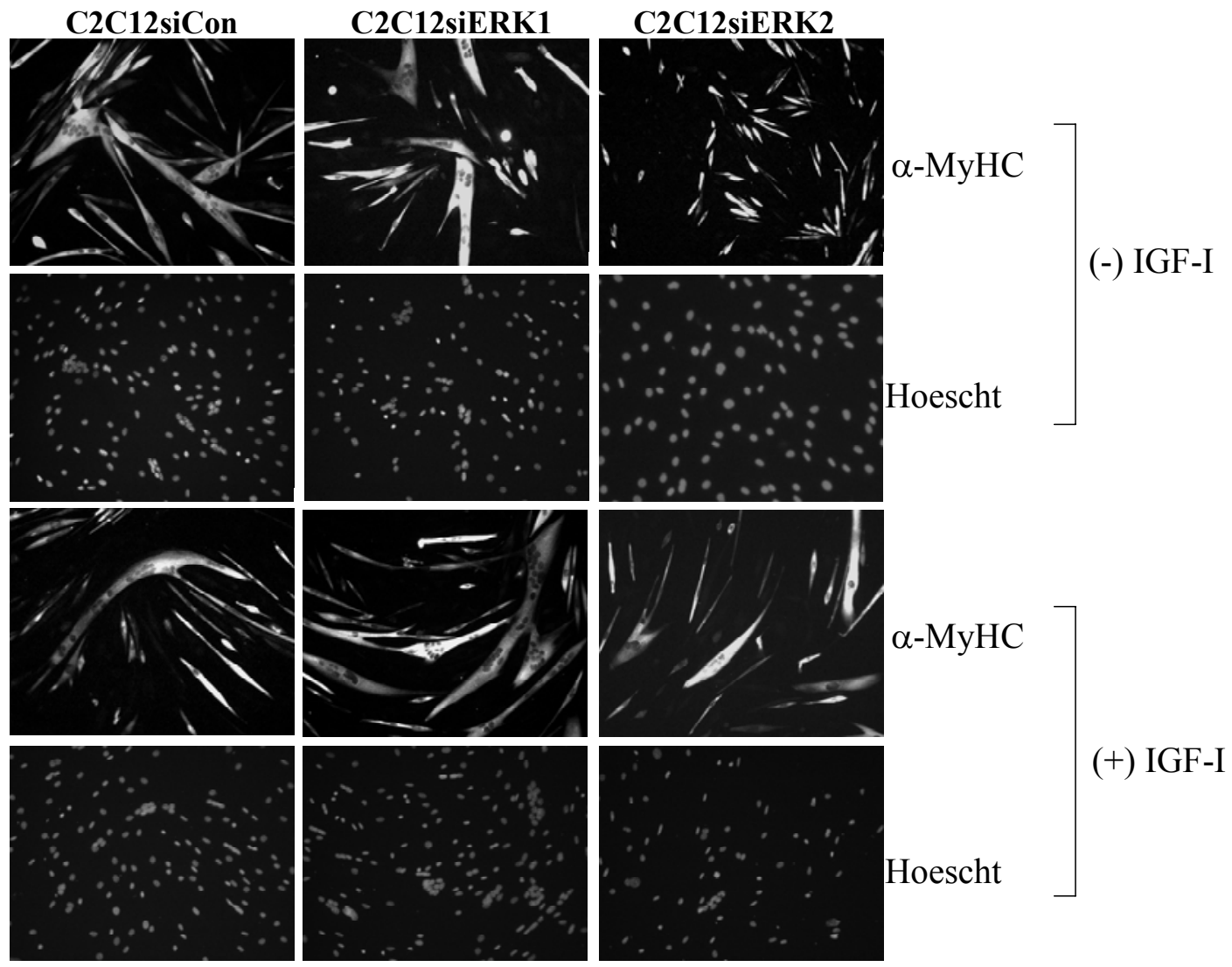

Figure 4-14. IGF-I treatment improves the differentiation capabilities of C2C12siERK2 myoblasts. C2C12siCon, C2C12siERK1 and C2C12siERK2 myoblasts were differentiated in the presence or absence of $250 \mathrm{ng} / \mathrm{mL}$ IGF-I for $48 \mathrm{~h}$. The cells were fixed and immunostained for myosin heavy chain expression. 


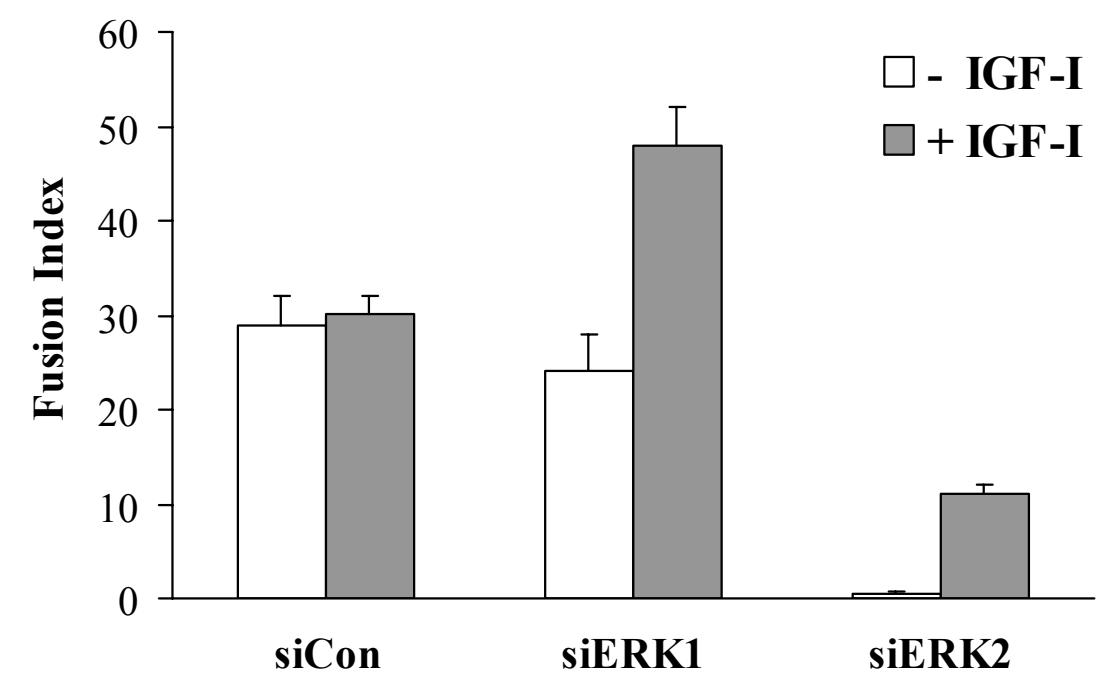

Figure 4-15. Myotube fusion index of IGF-I treated myoblasts. C2C12siCon, C2C12siERK1 and $\mathrm{C} 2 \mathrm{C} 12$ siERK2 myoblasts were differentiated in the presence or absence of $250 \mathrm{ng} / \mathrm{mL}$ IGF-I for $48 \mathrm{~h}$. The cells were fixed and immunostained for myosin heavy chain expression. The numbers of myofiber nuclei and total nuclei were counted in 10 random microscope fields under 200x. Fusion index was calculated as the number of $\mathrm{MyHC}(+)$ fibers containing two or more nuclei/total number of nuclei (x100). Means and standard errors of means from three independent experiments are shown. 


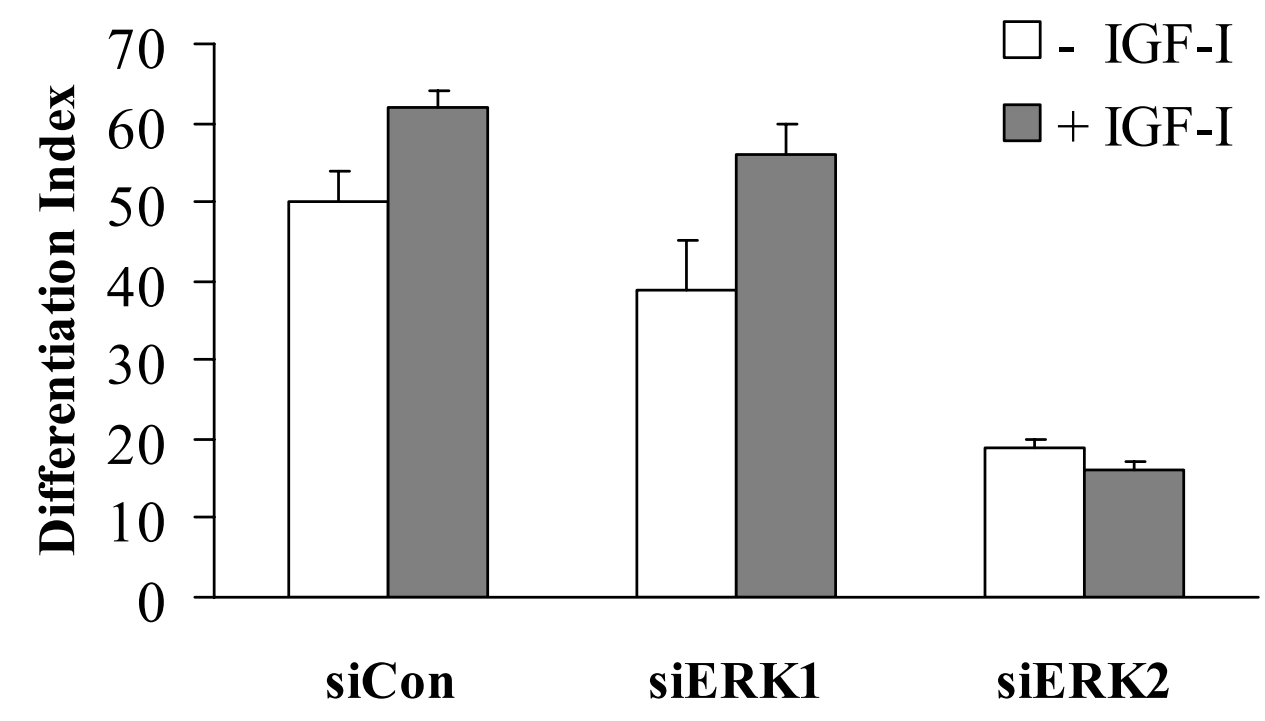

Figure 4-16. Differentiation index of IGF-I treated myoblasts. C2C12siCon, C2C12siERK1 and $\mathrm{C} 2 \mathrm{C} 12$ siERK2 myoblasts were differentiated in the presence or absence of $250 \mathrm{ng} / \mathrm{mL}$ IGF-I for $48 \mathrm{~h}$. The cells were fixed and immunostained for myosin heavy chain expression. The numbers of myofiber nuclei were and total nuclei were counted in 10 random microscope fields under 200x. Differentiation index was calculated as $\mathrm{MyHC}(+)$ nuclei/total nucleix 100. Means and standard errors of means from three independent experiments are shown. 




Figure 4-17. ERK2 insufficiency does not disrupt IGF-I induced Akt phosphorylation.

C2C12siCon, C2C12siERK1 and C2C12siERK2 myoblasts were differentiated in the presence or absence of $250 \mathrm{ng} / \mathrm{mL}$ IGF-I for $48 \mathrm{~h}$ prior to lysis. Equal amounts of protein were analyzed by Western blot for total and phosphorylated Akt and tubulin. IGF-I stimulates phosphorylation of Akt in all cell types. 



$$
\begin{array}{ll}
\alpha-\mathrm{MyHC} & \\
\text { (-) FGF2 }
\end{array}
$$


$(+)$ FGF2

Figure 4-18. FGF2 requires one functional ERK isoform to inhibit myogenic differentiation. C2C12siCon, C2C12siERK1 and C2C12siERK2 myoblasts were treated for $48 \mathrm{~h}$ differentiation -permissive medium supplemented with $5 \mathrm{ng} / \mathrm{mL}$ FGF2. Cultures were fixed and immunostained for myosin heavy chain expression. 




Figure 4-19. Differentiation index of FGF2 treated myoblasts. C2C12siCon, C2C12siERK1 and C2C12siERK2 myoblasts were treated for $48 \mathrm{~h}$ in differentiation-permissive medium supplemented with $5 \mathrm{ng} / \mathrm{mL}$ FGF2. Cultures were fixed and immunostained for myosin heavy chain expression. A differentiation index was calculated as the number of nuclei in $\mathrm{MyHC}(+)$ fiber/total number of nuclei x100. 


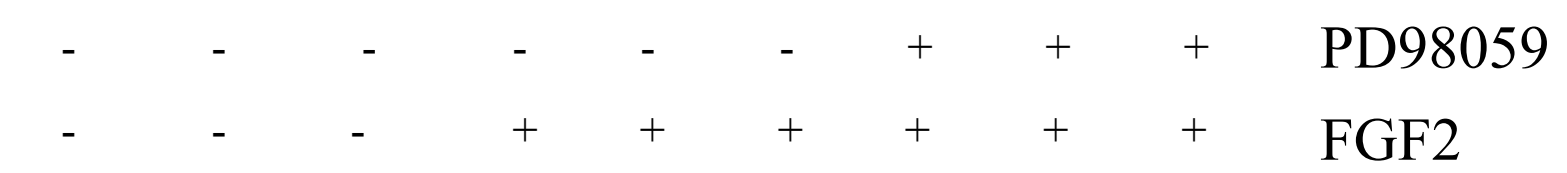

siCon siERK1 siERK2 siCon siERK1 siERK2 siCon siERK1 siERK2





$\alpha$-myogenin

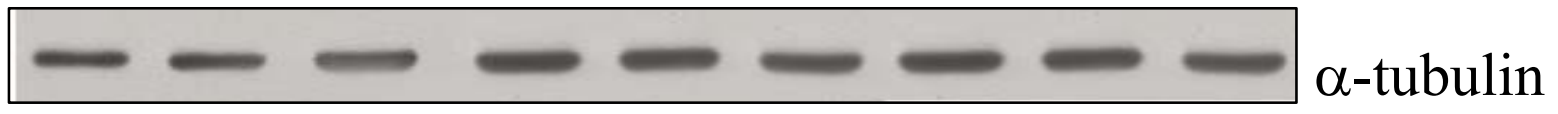

Figure 4-20. FGF2 inhibits myogenic differentiation through either ERK isoform. Parallel cultures of C2C12siCon, C2C12siERK1 and C2C12siERK2 were treated with $25 \mu \mathrm{M}$ PD98059 or DMSO. Lysates were analyzed by Western for myosin heavy chain, myogenin and tubulin. 


\section{CHAPTER 5}

DISCUSSION

ERK2 is obligatory for trophoblast proliferation, mesoderm differentiation, and protection from apoptosis, in vivo $[74 ; 119 ; 159 ; 210 ; 210]$. A dual role as a modulator of both proliferation and differentiation is reflected in myoblasts that are deficient in ERK2.

With regards to cell division, C2C12siERK2 myoblasts divide at a slower rate than ERK1 knockdown or control muscle cells. The reduced rate of proliferation by these cells is evident at low density whereby, the myoblasts have an extended doubling time of $2 \mathrm{~h}$ by comparison to controls. Interestingly, as the cells increase in density, a critical number is reached such that growth rates are comparable to control cells. This would argue that low-density C2C12siERK2 myoblasts are unable to produce, secrete, and/or respond to a factor needed for optimal growth. Alternatively, ERK2 deficient myoblasts may be more susceptible to apoptosis. ERK2 null embryos display elevated numbers of apoptotic cells that may be attributed to a failure to generate mesoderm [210]. We did not measure apoptosis directly, however, no striking increases in pycnotic nuclei or detached cells were observed in C2C12siERK2 myoblasts. The slower growth rate of myoblasts devoid of ERK2 also argues that ERK1 is unable to compensate for the proliferative effects of the ERK2 isoform. In myoblasts that contain adequate to elevated levels of functional ERK1, no detectable increase in growth rate or numbers of cells in S-phase was observed. These results are similar to those found in the ERK2 null embryo; pulse labeling studies demonstrated that wild-type and ERK2(-/-) embryos incorporated BrdU at equivalent rates and levels [210]. The mitogenic actions of ERK2 are further substantiated by reports that ERKI(-/-) mice are viable, fertile, and of normal size [116]. Our results demonstrate that loss of ERK2 causes a reduction in growth rate without altering the levels of phosphorylated or activated ERK1. Therefore, ERK1 cannot substitute for ERK2 as a modulator of cell division. 
The most prominent feature of ERK2 deficient myoblasts is their inability to form large multinucleated myofibers. C2C12siERK2 myoblasts undergo suboptimal differentiation that is characterized by a $50 \%$ reduction in the numbers of myosin expressing cells. Western blot analysis indicates that these myoblasts retain their myogenic identity as measured by their unperturbed expression of desmin. C2C12siERK2 muscle fibers are stunted and typified by a single myonuclei. The differentiation-defective phenotype is accredited to compromised ERK2 expression as treatment with a chemical inhibitor to prevent ERK1 activity does not re-establish muscle gene expression and morphological differentiation. Myogenin is required for terminal differentiation of myoblasts and myogenin (-/-) mice contain no myofibers [7;129;191]. ERK2 knockdown myoblasts produce limited amounts of myogenin protein and as predicted, the myoblasts are differentiation defective. The block to myofiber formation may be partially attributed to reduced myogenin expression. Supplementation of the culture medium with recombinant IGF-I restores myogenin protein synthesis to levels comparable to controls. However, the $\mathrm{C} 2 \mathrm{C} 12 \mathrm{siERK} 2$ myoblasts remain differentiation defective. An increase in the numbers of myofibers ( $>3$ myonuclei) is observed but these numbers are $60 \%$ lower than controls. Interestingly, C2C12siERK1 myoblasts that synthesize abundant amounts of ERK2 are more responsive to the actions of IGF-I. A 2-fold increase in the number of myonuclei found within mature fibers is noted. These results argue that ERK2 is necessary for myoblast fusion; loss of ERK2 inhibits fusion and overproduction of ERK2 promotes myogenesis.

Multiple reports detail growth factor induction of ERK1/2 activity that leads to an inhibition of myogenesis. Myostatin stimulates ERK1/2 phosphorylation that suppresses myogenin expression in a MEK-dependent manner [209]. Leukemia inhibitory factor (LIF) utilizes the Raf/MEK/ERK signaling cascade to inhibit $\mathrm{C} 2 \mathrm{C} 12$ differentiation and repression is 
relieved upon treatment with a MEK inhibitor [81]. FGF2, an ERK1/2 agonist, is regarded as a potent inhibitor of myogenesis [134]. FGF2 initiated ERK1/2 phosphorylation in C2C12 myoblasts and 23A2 myoblasts severely impairs biochemical and morphological measures of muscle differentiation; inhibition of ERK1/2 activation reinstates the muscle gene program $[179 ; 197]$. Our myoblast cell lines that are deficient in either ERK1 or ERK2 are responsive to the repressive actions of FGF2. Both $\mathrm{C} 2 \mathrm{C} 12$ siERK1 and $\mathrm{C} 2 \mathrm{C} 12 \mathrm{siERK} 2$ myoblasts fail to express markers of the terminal differentiation program in the presence of FGF2. The ability of FGF2 to severely restrict myogenesis in the ERK deficient myoblasts indicates that the growth factor indiscriminately utilizes either kinase isoform. Further support for this premise is demonstrated by restoration of myosin heavy chain and myogenin synthesis upon treatment with PD98059, a chemical MEK inhibitor. The restoration of myosin and myogenin expression does not reproduce wild-type levels thereby, suggesting that FGF2 uses additional signaling mechanism to impede myogenesis in its entirety. 


\section{CHAPTER 6 \\ IMPLICATIONS}

Skeletal muscle is the largest tissue in the body representing $70 \%$ of the body mass. It is responsible for the stability of body posture and body movement. Skeletal muscle cell differentiation is a complex system that is highly regulated. Many growth factors and hormones can control this process through activation of various intracellular signaling pathways. Among these signaling cascades, the ERK1/2 pathway is a key regulator of skeletal myogenesis.

The ERK1/2 signaling pathway plays an important role in skeletal muscle development, and is involved in the postnatal muscle growth, muscle repair and hypertrophy. This research focuses on the mechanism of how ERK1/2 work in vitro, which has potential use in human health and the meat industry.

Skeletal muscle hypertrophy and hyperplasia are two mechanisms that lead to an increase in muscle mass. Many signaling pathways are involved in this process. Naturally or induced mutations in some signal molecules can promote this process to increase muscle mass. For example, myostatin, a member of TGF- $\beta$ family, is an inhibitor of muscle differentiation. Mutation of myostatin can result in a heritable "double muscle" phenotype in cattle. Compared with normal cattle, myostatin-null cattle have an increased proficiency to convert feed into lean muscle and produce high quality meat with less bone, less fat and $20 \%$ more lean muscle on average [86]. From this study, ERK2 is required for myoblast differentiation. The ERK1deficient myoblast can fuse into fibers twice the size as control myoblast in response to IGF-I. This may be due to the ability of these cells to produce higher amount of ERK2. Thus, ERK2 
overexpression may be associated with muscle hypertrophy. When ERK2 is over-produced or has a higher level of phosphorylation, animals may have the similar muscle-hypertrophy phenotype. The advantage of the ERK2-induced hypertrophy is no extra hormone supplement is needed. This may bring a big benefit for the animal science and meat production.

Advanced age is associated with skeletal muscle atrophy. As people get older, there is a decrease in muscle mass as well as muscle function. There are age-related impairments in the muscle responsiveness to overload and injury. Genetic researchers suggest muscle-derived IGF-I instead of hepatic IGF-I is an important factor in maintaining muscle mass and repairing muscle damage in old age. As muscle gets older, there is an age-related decrease in the IGF-I response [55]. Based on this work, IGF-I can induce a higher level of myoblast differentiation in the ERK2 overexpressed myoblast. When ERK2 activity is higher in the aged muscle, there may be an increase in muscle mass and repair capability. As a result, age-associated muscle atrophy may be reduced through increasing ERK2 activity in skeletal muscle.

However, this work only focuses on the function of ERK2 in the cultured myoblast. It is crucial to build an in vivo model to verify the data from the in vitro experiments. An animal model with ERK2 protein knockdown or overexpression in skeletal muscle is a more powerful tool for examination of ERK2 function in vivo. 


\section{LIST OF REFERENCES}

[1] Adams RH, Porras A, Alonso G, Jones M, Vintersten K, Panelli S, Valladares A, Perez L, Klein R, Nebreda AR. Essential role of p38alpha MAP kinase in placental but not embryonic cardiovascular development. Mol Cell. 2000; 6(1):109-16.

[2] Adi S, Bin-Abbas B, Wu NY, Rosenthal SM. Early stimulation and late inhibition of extracellular signal-regulated kinase $1 / 2$ phosphorylation by IGF-I: a potential mechanism mediating the switch in IGF-I action on skeletal muscle cell differentiation. Endocrinology 2002; 143: 511-516.

[3] Adjei AA. Blocking oncogenic Ras signaling for cancer therapy. J. Natl. Cancer Inst. 2001; 93: 1062-1074.

[4] Al Khalili L, Bouzakri K, Glund S, Lonnqvist F, Koistinen HA, Krook A. Signaling specificity of interleukin-6 action on glucose and lipid metabolism in skeletal muscle. Mol. Endocrinol. 2006.

[5] Allen RE, Rankin LL, Greene EA, Boxhorn LK, Johnson SE, Taylor RG, Pierce PR. Desmin is present in proliferating rat muscle satellite cells but not in bovine muscle satellite cells. J. Cell Physiol 1991; 149: 525-535.

[6] Allen RE, Sheehan SM, Taylor RG, Kendall TL, Rice GM. Hepatocyte growth factor activates quiescent skeletal muscle satellite cells in vitro. J. Cell Physiol 1995; 165: 307-312.

[7] Arnold HH, Braun T. Targeted inactivation of myogenic factor genes reveals their role during mouse myogenesis: a review. Int. J. Dev. Biol. 1996; 40: 345-353.

[8] Baeza-Raja B, Munoz-Canoves P. p38 MAPK-induced nuclear factor-kappaB activity is required for skeletal muscle differentiation: role of interleukin-6. Mol. Biol. Cell 2004; 15: 2013-2026.

[9] Bain G, Engel I, Robanus Maandag EC, te Riele HP, Voland JR, Sharp LL, Chun J, Huey B, Pinkel D, Murre C. E2A deficiency leads to abnormalities in alphabeta T-cell development and to rapid development of T-cell lymphomas. Mol. Cell Biol. 1997; 17: 4782-4791.

[10] Bain G, Maandag EC, Izon DJ, Amsen D, Kruisbeek AM, Weintraub BC, Krop I, Schlissel MS, Feeney AJ, van Roon M, . E2A proteins are required for proper B cell development and initiation of immunoglobulin gene rearrangements. Cell 1994; 79: 885892.

[11] Bajard L, Relaix F, Lagha M, Rocancourt D, Daubas P, Buckingham ME. A novel genetic hierarchy functions during hypaxial myogenesis: Pax3 directly activates Myf5 in muscle progenitor cells in the limb. Genes Dev. 2006; 20: 2450-2464. 
[12] Baumann B, Weber CK, Troppmair J, Whiteside S, Israel A, Rapp UR, Wirth T. Raf induces NF-kappaB by membrane shuttle kinase MEKK1, a signaling pathway critical for transformation. Proc. Natl. Acad. Sci. U. S. A 2000; 97: 4615-4620.

[13] Beauchamp JR, Heslop L, Yu DS, Tajbakhsh S, Kelly RG, Wernig A, Buckingham ME, Partridge TA, Zammit PS. Expression of CD34 and Myf5 defines the majority of quiescent adult skeletal muscle satellite cells. J. Cell Biol. 2000; 151: 12211234.

[14] Belanger LF, Roy S, Tremblay M, Brott B, Steff AM, Mourad W, Hugo P, Erikson R, Charron J. Mek2 is dispensable for mouse growth and development. Mol. Cell Biol. 2003; 23: 4778-4787.

[15] Bladt F, Riethmacher D, Isenmann S, Aguzzi A, Birchmeier C. Essential role for the c-met receptor in the migration of myogenic precursor cells into the limb bud. Nature 1995; 376: 768-771.

[16] Bober E, Lyons GE, Braun T, Cossu G, Buckingham M, Arnold HH. The muscle regulatory gene, Myf-6, has a biphasic pattern of expression during early mouse development. J. Cell Biol. 1991; 113: 1255-1265.

[17] Bodine SC, Stitt TN, Gonzalez M, Kline WO, Stover GL, Bauerlein R, Zlotchenko E, Scrimgeour A, Lawrence JC, Glass DJ, Yancopoulos GD. Akt/mTOR pathway is a crucial regulator of skeletal muscle hypertrophy and can prevent muscle atrophy in vivo. Nat. Cell Biol. 2001; 3: 1014-1019.

[18] Brand-Saberi B, Christ B. Genetic and epigenetic control of muscle development in vertebrates. Cell Tissue Res. 1999; 296: 199-212.

[19] Braun T, Arnold HH. Inactivation of Myf-6 and Myf-5 genes in mice leads to alterations in skeletal muscle development. EMBO J. 1995; 14: 1176-1186.

[20] Braun T, Rudnicki MA, Arnold HH, Jaenisch R. Targeted inactivation of the muscle regulatory gene Myf-5 results in abnormal rib development and perinatal death. Cell 1992; 71: 369-382.

[21] Brunet A, Brondello JM, L'Allemain G, Lenormand P, McKenzie F, Pages G, Pouyssegur J. [MAP kinase module: role in the control of cell proliferation]. C. R. Seances Soc. Biol. Fil. 1995; 189: 43-57.

[22] Brunet A, Roux D, Lenormand P, Dowd S, Keyse S, Pouyssegur J. Nuclear translocation of p42/p44 mitogen-activated protein kinase is required for growth factorinduced gene expression and cell cycle entry. EMBO J. 1999; 18: 664-674.

[23] Bueno OF, Molkentin JD. Involvement of extracellular signal-regulated kinases 1/2 in cardiac hypertrophy and cell death. Circ. Res. 2002; 91: 776-781. 
[24] Chen WS, Xu PZ, Gottlob K, Chen ML, Sokol K, Shiyanova T, Roninson I, Weng W, Suzuki R, Tobe K, Kadowaki T, Hay N. Growth retardation and increased apoptosis in mice with homozygous disruption of the Akt1 gene. Genes Dev. 2001; 15: 2203-2208.

[25] Cheng TC, Tseng BS, Merlie JP, Klein WH, Olson EN. Activation of the myogenin promoter during mouse embryogenesis in the absence of positive autoregulation. Proc. Natl. Acad. Sci. U. S. A 1995; 92: 561-565.

[26] Cho H, Mu J, Kim JK, Thorvaldsen JL, Chu Q, Crenshaw EB, III, Kaestner KH, Bartolomei MS, Shulman GI, Birnbaum MJ. Insulin resistance and a diabetes mellitus-like syndrome in mice lacking the protein kinase Akt2 (PKB beta). Science. 2001; 292(5522): 1728-31

[27] Coleman ME, DeMayo F, Yin KC, Lee HM, Geske R, Montgomery C, Schwartz RJ. Myogenic vector expression of insulin-like growth factor I stimulates muscle cell differentiation and myofiber hypertrophy in transgenic mice. J. Biol. Chem. 1995; 270: 12109-12116.

[28] Conway K, Pin C, Kiernan JA, Merrifield P. The E protein HEB is preferentially expressed in developing muscle. Differentiation 2004; 72: 327-340.

[29] Coolican SA, Samuel DS, Ewton DZ, McWade FJ, Florini JR. The mitogenic and myogenic actions of insulin-like growth factors utilize distinct signaling pathways. J. Biol. Chem. 1997; 272: 6653-6662.

[30] Cooney RN, Maish GO, III, Gilpin T, Shumate ML, Lang CH, Vary TC. Mechanism of IL-1 induced inhibition of protein synthesis in skeletal muscle. Shock 1999; 11: $235-241$.

[31] Cooper RN, Tajbakhsh S, Mouly V, Cossu G, Buckingham M, Butler-Browne GS. In vivo satellite cell activation via Myf5 and MyoD in regenerating mouse skeletal muscle. J. Cell Sci.1999; 112(17): 2895-2901.

[32] Cornelison DD, Filla MS, Stanley HM, Rapraeger AC, Olwin BB. Syndecan-3 and syndecan-4 specifically mark skeletal muscle satellite cells and are implicated in satellite cell maintenance and muscle regeneration. Dev. Biol. 2001; 239: 79-94.

[33] Cornelison DD, Olwin BB, Rudnicki MA, Wold BJ. MyoD(-/-) satellite cells in single-fiber culture are differentiation defective and MRF4 deficient. Dev. Biol. 2000; 224: 122-137.

[34] Cornelison DD, Wilcox-Adelman SA, Goetinck PF, Rauvala H, Rapraeger AC, Olwin BB. Essential and separable roles for Syndecan-3 and Syndecan-4 in skeletal muscle development and regeneration. Genes Dev. 2004; 18: 2231-2236. 
[35] Cowley S, Paterson H, Kemp P, Marshall CJ. Activation of MAP kinase kinase is necessary and sufficient for PC12 differentiation and for transformation of NIH 3T3 cells. Cell 1994; 77: 841-852.

[36] Cross DA, Alessi DR, Cohen P, Andjelkovich M, Hemmings BA. Inhibition of glycogen synthase kinase- 3 by insulin mediated by protein kinase B. Nature 1995; 378 : 785-789.

[37] Daubas P, Tajbakhsh S, Hadchouel J, Primig M, Buckingham M. Myf5 is a novel early axonal marker in the mouse brain and is subjected to post-transcriptional regulation in neurons. Development 2000; 127: 319-331.

[38] De Angelis L, Borghi S, Melchionna R, Berghella L, Baccarani-Contri M, Parise F, Ferrari S, Cossu G. Inhibition of myogenesis by transforming growth factor beta is density-dependent and related to the translocation of transcription factor MEF2 to the cytoplasm. Proc. Natl. Acad. Sci. U. S. A 1998; 95: 12358-12363.

[39] De Angelis L, Zhao J, Andreucci JJ, Olson EN, Cossu G, McDermott JC. Regulation of vertebrate myotome development by the p38 MAP kinase-MEF2 signaling pathway. Dev. Biol. 2005; 283: 171-179.

[40] Deak M, Clifton AD, Lucocq LM, Alessi DR. Mitogen- and stress-activated protein kinase-1 (MSK1) is directly activated by MAPK and SAPK2/p38, and may mediate activation of CREB. EMBO J. 1998; 17: 4426-4441.

[41] DeChant AK, Dee K, Weyman CM. Raf-induced effects on the differentiation and apoptosis of skeletal myoblasts are determined by the level of Raf signaling: abrogation of apoptosis by Raf is downstream of caspase 3 activation. Oncogene 2002; 21: 5268-5279.

[42] Dee K, Freer M, Mei Y, Weyman CM. Apoptosis coincident with the differentiation of skeletal myoblasts is delayed by caspase 3 inhibition and abrogated by MEK-independent constitutive Ras signaling. Cell Death. Differ. 2002; 9: 209-218.

[43] DeVol DL, Rotwein P, Sadow JL, Novakofski J, Bechtel PJ. Activation of insulin-like growth factor gene expression during work-induced skeletal muscle growth. Am. J. Physiol 1990; 259: E89-E95.

[44] Dorman CM, Johnson SE. Activated Raf inhibits avian myogenesis through a MAPK-dependent mechanism. Oncogene 1999; 18: 5167-5176.

[45] Edmondson DG, Cheng TC, Cserjesi P, Chakraborty T, Olson EN. Analysis of the myogenin promoter reveals an indirect pathway for positive autoregulation mediated by the muscle-specific enhancer factor MEF-2. Mol. Cell Biol. 1992; 12: 3665-3677.

[46] Enslen H, Brancho DM, Davis RJ. Molecular determinants that mediate selective activation of p38 MAP kinase isoforms. EMBO J. 2000; 19: 1301-1311. 
[47] Errede B, Cade RM, Yashar BM, Kamada Y, Levin DE, Irie K, Matsumoto K. Dynamics and organization of MAP kinase signal pathways. Mol. Reprod. Dev. 1995; 42: 477-485.

[48] Evans WJ. Protein nutrition, exercise and aging. J. Am. Coll. Nutr. 2004; 23: 601S-609S.

[49] Fedorov YV, Rosenthal RS, Olwin BB. Oncogenic Ras-induced proliferation requires autocrine fibroblast growth factor 2 signaling in skeletal muscle cells. J. Cell Biol. 2001; 152: 1301-1305.

[50] Fernandez AM, Dupont J, Farrar RP, Lee S, Stannard B, Le Roith D. Musclespecific inactivation of the IGF-I receptor induces compensatory hyperplasia in skeletal muscle. J. Clin. Invest 2002; 109: 347-355.

[51] Ferrell JE, Jr. Tripping the switch fantastic: how a protein kinase cascade can convert graded inputs into switch-like outputs. Trends Biochem. Sci. 1996; 21: 460-466.

[52] Filvaroff EH, Ebner R, Derynck R. Inhibition of myogenic differentiation in myoblasts expressing a truncated type II TGF-beta receptor. Development 1994; 120 : 1085-1095.

[53] Flanagan-Steet H, Hannon K, McAvoy MJ, Hullinger R, Olwin BB. Loss of FGF receptor 1 signaling reduces skeletal muscle mass and disrupts myofiber organization in the developing limb. Dev. Biol. 2000; 218: 21-37.

[54] Florini JR, Ewton DZ, Coolican SA. Growth hormone and the insulin-like growth factor system in myogenesis. Endocr. Rev. 1996; 17: 481-517.

[55] Florini JR, Ewton DZ, Magri KA. Hormones, growth factors, and myogenic differentiation. Annu. Rev. Physiol 1991; 53: 201-216.

[56] Fowden AL. Endocrine regulation of fetal growth. Reprod. Fertil. Dev. 1995; 7: 351-363.

[57] Frisch H. Growth hormone and body composition in athletes. J. Endocrinol. Invest 1999; 22: 106-109.

[58] Fujii N, Boppart MD, Dufresne SD, Crowley PF, Jozsi AC, Sakamoto K, Yu H, Aschenbach WG, Kim S, Miyazaki H, Rui L, White MF, Hirshman MF, Goodyear LJ. Overexpression or ablation of JNK in skeletal muscle has no effect on glycogen synthase activity. Am. J. Physiol Cell Physiol 2004; 287: C200-C208.

[59] Fukuda M, Gotoh I, Adachi M, Gotoh Y, Nishida E. A novel regulatory mechanism in the mitogen-activated protein (MAP) kinase cascade. Role of nuclear export signal of MAP kinase kinase. J. Biol. Chem. 1997; 272: 32642-32648. 
[60] Fukuda M, Gotoh Y, Nishida E. Interaction of MAP kinase with MAP kinase kinase: its possible role in the control of nucleocytoplasmic transport of MAP kinase. EMBO J. 1997; 16: 1901-1908.

[61] Gal-Levi R, Leshem Y, Aoki S, Nakamura T, Halevy O. Hepatocyte growth factor plays a dual role in regulating skeletal muscle satellite cell proliferation and differentiation. Biochim. Biophys. Acta 1998; 1402: 39-51.

[62] Giroux S, Tremblay M, Bernard D, Cardin-Girard JF, Aubry S, Larouche L, Rousseau S, Huot J, Landry J, Jeannotte L, Charron J. Embryonic death of Mek1-deficient mice reveals a role for this kinase in angiogenesis in the labyrinthine region of the placenta. Curr. Biol. 1999; 9: 369-372.

[63] Glass DJ. Molecular mechanisms modulating muscle mass. Trends Mol. Med. 2003; 9: 344-350.

[64] Gong X, Wang X, Han J, Niesman I, Huang Q, Horwitz J. Development of cataractous macrophthalmia in mice expressing an active MEK1 in the lens. Invest Ophthalmol. Vis. Sci. 2001; 42: 539-548.

[65] Gossett LA, Kelvin DJ, Sternberg EA, Olson EN. A new myocyte-specific enhancer-binding factor that recognizes a conserved element associated with multiple muscle-specific genes. Mol. Cell Biol. 1989; 9: 5022-5033.

[66] Grayson J, Bassel-Duby R, Williams RS. Collaborative interactions between MEF-2 and Sp1 in muscle-specific gene regulation. J. Cell Biochem. 1998; 70: 366-375.

[67] Gredinger E, Gerber AN, Tamir Y, Tapscott SJ, Bengal E. Mitogen-activated protein kinase pathway is involved in the differentiation of muscle cells. J. Biol. Chem. 1998; 273: 10436-10444.

[68] Guttridge DC, Mayo MW, Madrid LV, Wang CY, Baldwin AS, Jr. NF-kappaBinduced loss of MyoD messenger RNA: possible role in muscle decay and cachexia. Science 2000; 289: 2363-2366.

[69] Hagemann C, Rapp UR. Isotype-specific functions of Raf kinases. Exp. Cell Res. 1999; 253: 34-46.

[70] Halevy O, Cantley LC. Differential regulation of the phosphoinositide 3-kinase and MAP kinase pathways by hepatocyte growth factor vs. insulin-like growth factor-I in myogenic cells. Exp. Cell Res. 2004; 297: 224-234.

[71] Hara K, Yonezawa K, Kozlowski MT, Sugimoto T, Andrabi K, Weng QP, Kasuga M, Nishimoto I, Avruch J. Regulation of eIF-4E BP1 phosphorylation by mTOR. J. Biol. Chem. 1997; 272: 26457-26463.

[72] Hardt SE, Sadoshima J. Glycogen synthase kinase-3beta: a novel regulator of cardiac hypertrophy and development. Circ. Res. 2002; 90: 1055-1063. 
[73] Hasty P, Bradley A, Morris JH, Edmondson DG, Venuti JM, Olson EN, Klein WH. Muscle deficiency and neonatal death in mice with a targeted mutation in the myogenin gene. Nature 1993; 364: 501-506.

[74] Hatano N, Mori Y, Oh-hora M, Kosugi A, Fujikawa T, Nakai N, Niwa H, Miyazaki J, Hamaoka T, Ogata M. Essential role for ERK2 mitogen-activated protein kinase in placental development. Genes Cells. 2003; 8(11):847-56

[75] Hawke TJ, Garry DJ. Myogenic satellite cells: physiology to molecular biology. J. Appl. Physiol 2001; 91: 534-551.

[76] Huesken D, Lange J, Mickanin C, Weiler J, Asselbergs F, Warner J, Meloon B, Engel S, Rosenberg A, Cohen D, Labow M, Reinhardt M, Natt F, Hall J. Design of a genome-wide siRNA library using an artificial neural network. Nat. Biotechnol. 2005; 23: 995-1001.

[77] Irintchev A, Zeschnigk M, Starzinski-Powitz A, Wernig A. Expression pattern of M-cadherin in normal, denervated, and regenerating mouse muscles. Dev. Dyn. 1994; 199: 326-337.

[78] Isaksson OG, Lindahl A, Nilsson A, Isgaard J. Action of growth hormone: current views. Acta Paediatr. Scand. Suppl 1988; 343: 12-18.

[79] Izquierdo M, Hakkinen K, Anton A, Garrues M, Ibanez J, Ruesta M, Gorostiaga EM. Maximal strength and power, endurance performance, and serum hormones in middle-aged and elderly men. Med Sci Sports Exerc. 2001; 33(9):1577-87.

[80] Jiang BH, Aoki M, Zheng JZ, Li J, Vogt PK. Myogenic signaling of phosphatidylinositol 3-kinase requires the serine-threonine kinase Akt/protein kinase B. Proc. Natl. Acad. Sci. U. S. A 1999; 96: 2077-2081.

[81] Jo C, Kim H, Jo I, Choi I, Jung SC, Kim J, Kim SS, Jo SA. Leukemia inhibitory factor blocks early differentiation of skeletal muscle cells by activating ERK. Biochim. Biophys. Acta 2005; 1743: 187-197.

[82] Johnson SE, Dorman CM, Bolanowski SA. Inhibition of myogenin expression by activated Raf is not responsible for the block to avian myogenesis. J. Biol. Chem. 2002; 277: 28742-28748.

[83] Jones NC, Fedorov YV, Rosenthal RS, Olwin BB. ERK1/2 is required for myoblast proliferation but is dispensable for muscle gene expression and cell fusion. $\mathrm{J}$. Cell Physiol 2001; 186: 104-115.

[84] Jones NC, Tyner KJ, Nibarger L, Stanley HM, Cornelison DD, Fedorov YV, Olwin BB. The p38 alpha\}/\{beta\} MAPK functions as a molecular switch to activate the quiescent satellite cell. J. Cell Biol. 2005; 169: 105-116. 
[85] Kaliman P, Vinals F, Testar X, Palacin M, Zorzano A. Phosphatidylinositol 3kinase inhibitors block differentiation of skeletal muscle cells. J. Biol. Chem. 1996; 271: 19146-19151.

[86] Kambadur R, Sharma M, Smith TP, Bass JJ. Mutations in myostatin (GDF8) in double-muscled Belgian Blue and Piedmontese cattle. Genome Res. 1997; 7: 910-916.

[87] Kasler HG, Victoria J, Duramad O, Winoto A. ERK5 is a novel type of mitogenactivated protein kinase containing a transcriptional activation domain. Mol. Cell Biol. 2000; 20: 8382-8389.

[88] Kato Y, Kravchenko VV, Tapping RI, Han J, Ulevitch RJ, Lee JD. BMK1/ERK5 regulates serum-induced early gene expression through transcription factor MEF2C. EMBO J. 1997; 16: 7054-7066.

[89] Kaufman SJ, Foster RF. Replicating myoblasts express a muscle-specific phenotype. Proc. Natl. Acad. Sci. U. S. A 1988; 85: 9606-9610.

[90] Kerkhoff E, Rapp UR. High-intensity Raf signals convert mitotic cell cycling into cellular growth. Cancer Res. 1998; 58: 1636-1640.

[91] Khurana A, Dey CS. Involvement of c-Jun N-terminal kinase activities in skeletal muscle differentiation. J. Muscle Res. Cell Motil. 2004; 25: 645-655.

[92] Knapp JR, Davie JK, Myer A, Meadows E, Olson EN, Klein WH. Loss of myogenin in postnatal life leads to normal skeletal muscle but reduced body size. Development 2006; 133: 601-610.

[93] Kontaridis MI, Liu X, Zhang L, Bennett AM. SHP-2 complex formation with the SHP-2 substrate-1 during C2C12 myogenesis. J. Cell Sci. 2001; 114: 2187-2198.

[94] Kuan CY, Yang DD, Samanta Roy DR, Davis RJ, Rakic P, Flavell RA. The Jnk1 and Jnk2 protein kinases are required for regional specific apoptosis during early brain development. Neuron 1999; 22: 667-676.

[95] Kuida K, Boucher DM. Functions of MAP kinases: insights from gene-targeting studies. J. Biochem. (Tokyo) 2004; 135: 653-656.

[96] Lai KM, Gonzalez M, Poueymirou WT, Kline WO, Na E, Zlotchenko E, Stitt TN, Economides AN, Yancopoulos GD, Glass DJ. Conditional activation of akt in adult skeletal muscle induces rapid hypertrophy. Mol. Cell Biol. 2004; 24: 9295-9304.

[97] Lassar AB, Davis RL, Wright WE, Kadesch T, Murre C, Voronova A, Baltimore D, Weintraub H. Functional activity of myogenic HLH proteins requires heterooligomerization with E12/E47-like proteins in vivo. Cell 1991; 66: 305-315.

[98] Lassar AB, Munsterberg AE. The role of positive and negative signals in somite patterning. Curr. Opin. Neurobiol. 1996; 6: 57-63. 
[99] Lavoie JN, L'Allemain G, Brunet A, Muller R, Pouyssegur J. Cyclin D1 expression is regulated positively by the p42/p44MAPK and negatively by the p38/HOGMAPK pathway. J. Biol. Chem. 1996; 271: 20608-20616.

[100] Le Gall M, Chambard JC, Breittmayer JP, Grall D, Pouyssegur J, ObberghenSchilling E. The p42/p44 MAP kinase pathway prevents apoptosis induced by anchorage and serum removal. Mol Biol Cell. 2000; 11(3):1103-12.

[101] Lehmann K, Janda E, Pierreux CE, Rytomaa M, Schulze A, McMahon M, Hill CS, Beug H, Downward J. Raf induces TGFbeta production while blocking its apoptotic but not invasive responses: a mechanism leading to increased malignancy in epithelial cells. Genes Dev. 2000; 14: 2610-2622.

[102] Leshem Y, Gitelman I, Ponzetto C, Halevy O. Preferential binding of Grb2 or phosphatidylinositol 3-kinase to the met receptor has opposite effects on HGF-induced myoblast proliferation. Exp. Cell Res. 2002; 274: 288-298.

[103] Leshem Y, Spicer DB, Gal-Levi R, Halevy O. Hepatocyte growth factor (HGF) inhibits skeletal muscle cell differentiation: a role for the bHLH protein twist and the cdk inhibitor p27. J. Cell Physiol 2000; 184: 101-109.

[104] Lewis TS, Shapiro PS, Ahn NG. Signal transduction through MAP kinase cascades. Adv. Cancer Res. 1998; 74: 49-139.

[105] Li Y, Jiang B, Ensign WY, Vogt PK, Han J. Myogenic differentiation requires signalling through both phosphatidylinositol 3-kinase and p38 MAP kinase. Cell Signal. 2000; 12: 751-757.

[106] Lilly B, Zhao B, Ranganayakulu G, Paterson BM, Schulz RA, Olson EN. Requirement of MADS domain transcription factor D-MEF2 for muscle formation in Drosophila. Science 1995; 267: 688-693.

[107] Lin Q, Schwarz J, Bucana C, Olson EN. Control of mouse cardiac morphogenesis and myogenesis by transcription factor MEF2C. Science 1997; 276: 1404-1407.

[108] Liu D, Black BL, Derynck R. TGF-beta inhibits muscle differentiation through functional repression of myogenic transcription factors by Smad3. Genes Dev. 2001; 15: 2950-2966.

[109] Liu JP, Baker J, Perkins AS, Robertson EJ, Efstratiadis A. Mice carrying null mutations of the genes encoding insulin-like growth factor I (Igf-1) and type 1 IGF receptor (Igf1r). Cell 1993; 75: 59-72.

[110] Lluis F, Ballestar E, Suelves M, Esteller M, Munoz-Canoves P. E47 phosphorylation by 38 MAPK promotes MyoD/E47 association and muscle-specific gene transcription. EMBO J. 2005; 24: 974-984. 
[111] Loughna PT, Bates PC. Interactions between growth hormone and nutrition in hypophysectomised rats: skeletal muscle myosin heavy chain mRNA levels. Biochem. Biophys. Res. Commun. 1994; 198: 97-102.

[112] Lowy DR, Willumsen BM. Function and regulation of ras. Annu. Rev. Biochem. 1993; 62: 851-891.

[113] Lupu F, Terwilliger JD, Lee K, Segre GV, Efstratiadis A. Roles of growth hormone and insulin-like growth factor 1 in mouse postnatal growth. Dev. Biol. 2001; 229: $141-162$.

[114] Mathews LS, Hammer RE, Behringer RR, D'Ercole AJ, Bell GI, Brinster RL, Palmiter RD. Growth enhancement of transgenic mice expressing human insulin-like growth factor I. Endocrinology 1988; 123: 2827-2833.

[115] MAURO A. Satellite cell of skeletal muscle fibers. J. Biophys. Biochem. Cytol. 1961; 9: 493-495.

[116] Mazzucchelli C, Vantaggiato C, Ciamei A, Fasano S, Pakhotin P, Krezel W, Welzl H, Wolfer DP, Pages G, Valverde O, Marowsky A, Porrazzo A, Orban PC, Maldonado R, Ehrengruber MU, Cestari V, Lipp HP, Chapman PF, Pouyssegur J, Brambilla R. Knockout of ERK1 MAP kinase enhances synaptic plasticity in the striatum and facilitates striatal-mediated learning and memory. Neuron 2002; 34: 807-820.

[117] McPherron AC, Lawler AM, Lee SJ. Regulation of skeletal muscle mass in mice by a new TGF-beta superfamily member. Nature 1997; 387: 83-90.

[118] Megeney LA, Kablar B, Garrett K, Anderson JE, Rudnicki MA. MyoD is required for myogenic stem cell function in adult skeletal muscle. Genes Dev. 1996; 10: 1173-1183.

[119] Meloche S, Vella FD, Voisin L, Ang SL, Saba-El-Leil M. Erk2 signaling and early embryo stem cell self-renewal. Cell Cycle 2004; 3: 241-243.

[120] Milasincic DJ, Calera MR, Farmer SR, Pilch PF. Stimulation of C2C12 myoblast growth by basic fibroblast growth factor and insulin-like growth factor 1 can occur via mitogen-activated protein kinase-dependent and -independent pathways. Mol. Cell Biol. 1996; 16: 5964-5973.

[121] Minden A, Karin M. Regulation and function of the JNK subgroup of MAP kinases. Biochim. Biophys. Acta 1997; 1333: F85-104.

[122] Moelling K, Schad K, Bosse M, Zimmermann S, Schweneker M. Regulation of Raf-Akt Cross-talk. J. Biol. Chem. 2002; 277: 31099-31106.

[123] Molkentin JD, Black BL, Martin JF, Olson EN. Cooperative activation of muscle gene expression by MEF2 and myogenic bHLH proteins. Cell 1995; 83: 1125-1136. 
[124] Mor A, Philips MR. Compartmentalized Ras/MAPK signaling. Annu. Rev. Immunol. 2006; 24: 771-800.

[125] Morrison DK, Cutler RE. The complexity of Raf-1 regulation. Curr. Opin. Cell Biol. 1997; 9: 174-179.

[126] Moss FP, Leblond CP. Satellite cells as the source of nuclei in muscles of growing rats. Anat. Rec. 1971; 170: 421-435.

[127] Mudgett JS, Ding J, Guh-Siesel L, Chartrain NA, Yang L, Gopal S, Shen MM. Essential role for p38alpha mitogen-activated protein kinase in placental angiogenesis. Proc. Natl. Acad. Sci. U. S. A 2000; 97: 10454-10459.

[128] Mulder KM. Role of Ras and Mapks in TGFbeta signaling. Cytokine Growth Factor Rev. 2000; 11: 23-35.

[129] Nabeshima Y, Hanaoka K, Hayasaka M, Esumi E, Li S, Nonaka I, Nabeshima Y. Myogenin gene disruption results in perinatal lethality because of severe muscle defect. Nature 1993; 364: 532-535.

[130] Naya FJ, Wu C, Richardson JA, Overbeek P, Olson EN. Transcriptional activity of MEF2 during mouse embryogenesis monitored with a MEF2-dependent transgene. Development 1999; 126: 2045-2052.

[131] O'Neill E, Kolch W. Taming the Hippo: Raf-1 Controls Apoptosis by Suppressing MST2/Hippo. Cell Cycle 2005; 4.

[132] Olguin HC, Olwin BB. Pax-7 up-regulation inhibits myogenesis and cell cycle progression in satellite cells: a potential mechanism for self-renewal. Dev. Biol. 2004; 275 : 375-388.

[133] Olson EN, Arnold HH, Rigby PW, Wold BJ. Know your neighbors: three phenotypes in null mutants of the myogenic bHLH gene MRF4. Cell 1996; 85: 1-4.

[134] Olwin BB, Hannon K, Kudla AJ. Are fibroblast growth factors regulators of myogenesis in vivo? Prog. Growth Factor Res. 1994; 5: 145-158.

[135] Ott MO, Bober E, Lyons G, Arnold H, Buckingham M. Early expression of the myogenic regulatory gene, myf-5, in precursor cells of skeletal muscle in the mouse embryo. Development 1991; 111: 1097-1107.

[136] Oustanina S, Hause G, Braun T. Pax7 directs postnatal renewal and propagation of myogenic satellite cells but not their specification. EMBO J. 2004; 23: 3430-3439.

[137] Pages G, Guerin S, Grall D, Bonino F, Smith A, Anjuere F, Auberger P, Pouyssegur J. Defective thymocyte maturation in p44 MAP kinase (Erk 1) knockout mice. Science $1999 ; 286:$ 1374-1377. 
[138] Pallafacchina G, Calabria E, Serrano AL, Kalhovde JM, Schiaffino S. A protein kinase B-dependent and rapamycin-sensitive pathway controls skeletal muscle growth but not fiber type specification. Proc. Natl. Acad. Sci. U. S. A 2002; 99: 9213-9218.

[139] Patapoutian A, Yoon JK, Miner JH, Wang S, Stark K, Wold B. Disruption of the mouse MRF4 gene identifies multiple waves of myogenesis in the myotome. Development $1995 ; 121: 3347-3358$.

[140] Pearson G, Robinson F, Beers GT, Xu BE, Karandikar M, Berman K, Cobb MH. Mitogen-activated protein (MAP) kinase pathways: regulation and physiological functions. Endocr. Rev. 2001; 22: 153-183.

[141] Pedersen BK, Steensberg A, Schjerling P. Muscle-derived interleukin-6: possible biological effects. J. Physiol 2001; 536: 329-337.

[142] Penn BH, Bergstrom DA, Dilworth FJ, Bengal E, Tapscott SJ. A MyoD-generated feed-forward circuit temporally patterns gene expression during skeletal muscle differentiation. Genes Dev. 2004; 18: 2348-2353.

[143] Perry RL, Parker MH, Rudnicki MA. Activated MEK1 binds the nuclear MyoD transcriptional complex to repress transactivation. Mol. Cell 2001; 8: 291-301.

[144] Pinset C, Garcia A, Rousse S, Dubois C, Montarras D. Wortmannin inhibits IGFdependent differentiation in the mouse myogenic cell line C2. C. R. Acad. Sci. III 1997; 320: $367-374$.

[145] Pritchard CA, Bolin L, Slattery R, Murray R, McMahon M. Post-natal lethality and neurological and gastrointestinal defects in mice with targeted disruption of the A-Raf protein kinase gene. Curr. Biol. 1996; 6: 614-617.

[146] Ramocki MB, Johnson SE, White MA, Ashendel CL, Konieczny SF, Taparowsky EJ. Signaling through mitogen-activated protein kinase and Rac/Rho does not duplicate the effects of activated Ras on skeletal myogenesis. Mol. Cell Biol. 1997; 17: 3547-3555.

[147] Rapp UR, Goldsborough MD, Mark GE, Bonner TI, Groffen J, Reynolds FH, Jr., Stephenson JR. Structure and biological activity of v-raf, a unique oncogene transduced by a retrovirus. Proc. Natl. Acad. Sci. U. S. A 1983; 80: 4218-4222.

[148] Rawls A, Morris JH, Rudnicki M, Braun T, Arnold HH, Klein WH, Olson EN. Myogenin's functions do not overlap with those of MyoD or Myf-5 during mouse embryogenesis. Dev. Biol. 1995; 172: 37-50.

[149] Rawls A, Valdez MR, Zhang W, Richardson J, Klein WH, Olson EN. Overlapping functions of the myogenic bHLH genes MRF4 and MyoD revealed in double mutant mice. Development 1998; 125: 2349-2358. 
[150] Regan CP, Li W, Boucher DM, Spatz S, Su MS, Kuida K. Erk5 null mice display multiple extraembryonic vascular and embryonic cardiovascular defects. Proc Natl Acad Sci U S A. 2002; 99(14): 9248-53

[151] Relaix F, Montarras D, Zaffran S, Gayraud-Morel B, Rocancourt D, Tajbakhsh S, Mansouri A, Cumano A, Buckingham M. Pax3 and Pax7 have distinct and overlapping functions in adult muscle progenitor cells. J. Cell Biol. 2006; 172: 91-102.

[152] Relaix F, Rocancourt D, Mansouri A, Buckingham M. A Pax3/Pax7-dependent population of skeletal muscle progenitor cells. Nature 2005; 435: 948-953.

[153] Rodriguez-Viciana P, Warne PH, Dhand R, Vanhaesebroeck B, Gout I, Fry MJ, Waterfield MD, Downward J. Phosphatidylinositol-3-OH kinase as a direct target of Ras. Nature 1994; 370: 527-532.

[154] Rommel C, Bodine SC, Clarke BA, Rossman R, Nunez L, Stitt TN, Yancopoulos GD, Glass DJ. Mediation of IGF-1-induced skeletal myotube hypertrophy by $\mathrm{PI}(3) \mathrm{K} / \mathrm{Akt} / \mathrm{mTOR}$ and PI(3)K/Akt/GSK3 pathways. Nat. Cell Biol. 2001; 3: 1009-1013.

[155] Rommel C, Clarke BA, Zimmermann S, Nunez L, Rossman R, Reid K, Moelling K, Yancopoulos GD, Glass DJ. Differentiation stage-specific inhibition of the Raf-MEKERK pathway by Akt. Science 1999; 286: 1738-1741.

[156] Roovers K, Assoian RK. Integrating the MAP kinase signal into the G1 phase cell cycle machinery. Bioessays 2000; 22: 818-826.

[157] Rudnicki MA, Braun T, Hinuma S, Jaenisch R. Inactivation of MyoD in mice leads to up-regulation of the myogenic HLH gene Myf-5 and results in apparently normal muscle development. Cell 1992; 71: 383-390.

[158] Rudnicki MA, Schnegelsberg PN, Stead RH, Braun T, Arnold HH, Jaenisch R. MyoD or Myf-5 is required for the formation of skeletal muscle. Cell 1993; 75: 13511359.

[159] Saba-El-Leil MK, Vella FD, Vernay B, Voisin L, Chen L, Labrecque N, Ang SL, Meloche S. An essential function of the mitogen-activated protein kinase Erk2 in mouse trophoblast development. EMBO Rep. 2003; 4: 964-968.

[160] Sabapathy K, Hu Y, Kallunki T, Schreiber M, David JP, Jochum W, Wagner EF, Karin M. JNK2 is required for efficient T-cell activation and apoptosis but not for normal lymphocyte development. Curr. Biol. 1999; 9: 116-125.

[161] Sabapathy K, Jochum W, Hochedlinger K, Chang L, Karin M, Wagner EF. Defective neural tube morphogenesis and altered apoptosis in the absence of both JNK1 and JNK2. Mech. Dev. 1999; 89: 115-124. 
[162] Sabapathy K, Kallunki T, David JP, Graef I, Karin M, Wagner EF. c-Jun NH2terminal kinase (JNK) 1 and JNK2 have similar and stage-dependent roles in regulating $\mathrm{T}$ cell apoptosis and proliferation. J. Exp. Med. 2001; 193: 317-328.

[163] Sassoon D, Lyons G, Wright WE, Lin V, Lassar A, Weintraub H, Buckingham M. Expression of two myogenic regulatory factors myogenin and MyoD1 during mouse embryogenesis. Nature 1989; 341: 303-307.

[164] Schaeffer HJ, Catling AD, Eblen ST, Collier LS, Krauss A, Weber MJ. MP1: a MEK binding partner that enhances enzymatic activation of the MAP kinase cascade. Science 1998; 281: 1668-1671.

[165] Scholl FA, Dumesic PA, Khavari PA. Mek1 alters epidermal growth and differentiation. Cancer Res. 2004; 64: 6035-6040.

[166] Schultz E. Satellite cell proliferative compartments in growing skeletal muscles. Dev. Biol. 1996; 175: 84-94.

[167] Schultz E, Gibson MC, Champion T. Satellite cells are mitotically quiescent in mature mouse muscle: an EM and radioautographic study. J. Exp. Zool. 1978; 206: 451456.

[168] Seale P, Sabourin LA, Girgis-Gabardo A, Mansouri A, Gruss P, Rudnicki MA. Pax7 is required for the specification of myogenic satellite cells. Cell 2000; 102: 777-786.

[169] Sewing A, Wiseman B, Lloyd AC, Land H. High-intensity Raf signal causes cell cycle arrest mediated by p21Cip1. Mol. Cell Biol. 1997; 17: 5588-5597.

[170] Shindoh C, Hida W, Ohkawara Y, Yamauchi K, Ohno I, Takishima T, Shirato K. TNF-alpha mRNA expression in diaphragm muscle after endotoxin administration. Am. J. Respir. Crit Care Med. 1995; 152: 1690-1696.

[171] Sjogren K, Liu JL, Blad K, Skrtic S, Vidal O, Wallenius V, LeRoith D, Tornell J, Isaksson OG, Jansson JO, Ohlsson C. Liver-derived insulin-like growth factor I (IGF-I) is the principal source of IGF-I in blood but is not required for postnatal body growth in mice. Proc. Natl. Acad. Sci. U. S. A 1999; 96: 7088-7092.

[172] Snow MH. A quantitative ultrastructural analysis of satellite cells in denervated fast and slow muscles of the mouse. Anat. Rec. 1983; 207: 593-604.

[173] Sohn SJ, Sarvis BK, Cado D, Winoto A. ERK5 MAPK regulates embryonic angiogenesis and acts as a hypoxia-sensitive repressor of vascular endothelial growth factor expression. J. Biol. Chem. 2002; 277: 43344-43351.

[174] Sugiura N, Suga T, Ozeki Y, Mamiya G, Takishima K. The mouse extracellular signal-regulated kinase 2 gene. Gene structure and characterization of the promoter. J.

Biol. Chem. 1997; 272: 21575-21581. 
[175] Summerbell D, Halai C, Rigby PW. Expression of the myogenic regulatory factor Mrf4 precedes or is contemporaneous with that of Myf5 in the somitic bud. Mech. Dev. 2002; 117: 331-335.

[176] Thomas M, Langley B, Berry C, Sharma M, Kirk S, Bass J, Kambadur R. Myostatin, a negative regulator of muscle growth, functions by inhibiting myoblast proliferation. J. Biol. Chem. 2000; 275: 40235-40243.

[177] Tiffin N, Adi S, Stokoe D, Wu NY, Rosenthal SM. Akt phosphorylation is not sufficient for insulin-like growth factor-stimulated myogenin expression but must be accompanied by down-regulation of mitogen-activated protein kinase/extracellular signalregulated kinase phosphorylation. Endocrinology 2004; 145: 4991-4996.

[178] Tomiya A, Aizawa T, Nagatomi R, Sensui H, Kokubun S. Myofibers express IL-6 after eccentric exercise. Am. J. Sports Med. 2004; 32: 503-508.

[179] Tortorella LL, Milasincic DJ, Pilch PF. Critical proliferation-independent window for basic fibroblast growth factor repression of myogenesis via the p42/p44 MAPK signaling pathway. J. Biol. Chem. 2001; 276: 13709-13717.

[180] Tournier C, Hess P, Yang DD, Xu J, Turner TK, Nimnual A, Bar-Sagi D, Jones SN, Flavell RA, Davis RJ. Requirement of JNK for stress-induced activation of the cytochrome c-mediated death pathway. Science 2000; 288: 870-874.

[181] Tsujinaka T, Ebisui C, Fujita J, Kishibuchi M, Morimoto T, Ogawa A, Katsume A, Ohsugi Y, Kominami E, Monden M. Muscle undergoes atrophy in association with increase of lysosomal cathepsin activity in interleukin-6 transgenic mouse. Biochem. Biophys. Res. Commun. 1995; 207: 168-174.

[182] Tsujinaka T, Fujita J, Ebisui C, Yano M, Kominami E, Suzuki K, Tanaka K, Katsume A, Ohsugi Y, Shiozaki H, Monden M. Interleukin 6 receptor antibody inhibits muscle atrophy and modulates proteolytic systems in interleukin 6 transgenic mice. J. Clin. Invest 1996; 97: 244-249.

[183] Tureckova J, Wilson EM, Cappalonga JL, Rotwein P. Insulin-like growth factormediated muscle differentiation: collaboration between phosphatidylinositol 3-kinase-Aktsignaling pathways and myogenin. J. Biol. Chem. 2001; 276: 39264-39270.

[184] Ussar S, Voss T. MEK1 and MEK2, different regulators of the G1/S transition. J. Biol. Chem. 2004; 279: 43861-43869.

[185] Valdez MR, Richardson JA, Klein WH, Olson EN. Failure of Myf5 to support myogenic differentiation without myogenin, MyoD, and MRF4. Dev. Biol. 2000; 219: 287-298.

[186] Vandenburgh HH, Karlisch P, Shansky J, Feldstein R. Insulin and IGF-I induce pronounced hypertrophy of skeletal myofibers in tissue culture. Am. J. Physiol 1991; 260: C475-C484. 
[187] Vary TC. Regulation of skeletal muscle protein turnover during sepsis. Curr. Opin. Clin. Nutr. Metab Care 1998; 1:217-224.

[188] Vercoutter-Edouart AS, Lemoine J, Le B, X, Louis H, Boilly B, Nurcombe V, Revillion F, Peyrat JP, Hondermarck H. Proteomic analysis reveals that 14-3-3sigma is down-regulated in human breast cancer cells. Cancer Res. 2001; 61: 76-80.

[189] Vermeulen A, Goemaere S, Kaufman JM. Testosterone, body composition and aging. J. Endocrinol. Invest 1999; 22: 110-116.

[190] Vivanco I, Sawyers CL. The phosphatidylinositol 3-Kinase AKT pathway in human cancer. Nat. Rev. Cancer 2002; 2: 489-501.

[191] Vivian JL, Gan L, Olson EN, Klein WH. A hypomorphic myogenin allele reveals distinct myogenin expression levels required for viability, skeletal muscle development, and sternum formation. Dev. Biol. 1999; 208: 44-55.

[192] von Haehling S, Genth-Zotz S, Anker SD, Volk HD. Cachexia: a therapeutic approach beyond cytokine antagonism. Int. J. Cardiol. 2002; 85: 173-183.

[193] Wang X, Thomson SR, Starkey JD, Page JL, Ealy AD, Johnson SE. Transforming growth factor beta1 is up-regulated by activated Raf in skeletal myoblasts but does not contribute to the differentiation-defective phenotype. J. Biol. Chem. 2004; 279: 2528-2534.

[194] Weintraub H, Davis R, Tapscott S, Thayer M, Krause M, Benezra R, Blackwell TK, Turner D, Rupp R, Hollenberg S, . The myoD gene family: nodal point during specification of the muscle cell lineage. Science 1991; 251: 761-766.

[195] Weyman CM, Ramocki MB, Taparowsky EJ, Wolfman A. Distinct signaling pathways regulate transformation and inhibition of skeletal muscle differentiation by oncogenic Ras. Oncogene 1997; 14: 697-704.

[196] Weyman CM, Wolfman A. Oncogenic Ras-induced secretion of a novel inhibitor of skeletal myoblast differentiation. Oncogene 1997; 15: 2521-2528.

[197] Weyman CM, Wolfman A. Mitogen-activated protein kinase kinase (MEK) activity is required for inhibition of skeletal muscle differentiation by insulin-like growth factor 1 or fibroblast growth factor 2. Endocrinology 1998; 139: 1794-1800.

[198] White JD, Scaffidi A, Davies M, McGeachie J, Rudnicki MA, Grounds MD. Myotube formation is delayed but not prevented in MyoD-deficient skeletal muscle: studies in regenerating whole muscle grafts of adult mice. J. Histochem. Cytochem. 2000; 48: 1531-1544.

[199] Winter B, Arnold HH. Activated raf kinase inhibits muscle cell differentiation through a MEF2-dependent mechanism. J. Cell Sci. 2000; 113 Pt 23: 4211-4220. 
[200] Winter B, Arnold HH. Activated raf kinase inhibits muscle cell differentiation through a MEF2-dependent mechanism. J. Cell Sci. 2000; 113 Pt 23: 4211-4220.

[201] Wojnowski L, Stancato LF, Zimmer AM, Hahn H, Beck TW, Larner AC, Rapp UR, Zimmer A. Craf-1 protein kinase is essential for mouse development. Mech. Dev. 1998; 76: 141-149.

[202] Wojnowski L, Zimmer AM, Beck TW, Hahn H, Bernal R, Rapp UR, Zimmer A. Endothelial apoptosis in Braf-deficient mice. Nat Genet 1997;16(3):293-7.

[203] Woo RA, Poon RY. Cyclin-dependent kinases and S phase control in mammalian cells. Cell Cycle 2003; 2: 316-324.

[204] Wu Z, Woodring PJ, Bhakta KS, Tamura K, Wen F, Feramisco JR, Karin M, Wang JY, Puri PL. p38 and extracellular signal-regulated kinases regulate the myogenic program at multiple steps. Mol. Cell Biol. 2000; 20: 3951-3964.

[205] Yamada S, Buffinger N, DiMario J, Strohman RC. Fibroblast growth factor is stored in fiber extracellular matrix and plays a role in regulating muscle hypertrophy. Med. Sci. Sports Exerc. 1989; 21: S173-S180.

[206] Yan L, Carr J, Ashby PR, Murry-Tait V, Thompson C, Arthur JS. Knockout of ERK 5 causes multiple defects in placental and embryonic development. BMC. Dev. Biol. 2003; 3: 11 .

[207] Yang CC, Ornatsky OI, McDermott JC, Cruz TF, Prody CA. Interaction of myocyte enhancer factor 2 (MEF2) with a mitogen-activated protein kinase, ERK5/BMK1. Nucleic Acids Res. 1998; 26: 4771-4777.

[208] Yang DD, Kuan CY, Whitmarsh AJ, Rincon M, Zheng TS, Davis RJ, Rakic P, Flavell RA. Absence of excitotoxicity-induced apoptosis in the hippocampus of mice lacking the Jnk3 gene. Nature 1997; 389: 865-870.

[209] Yang W, Chen Y, Zhang Y, Wang X, Yang N, Zhu D. Extracellular signalregulated kinase $1 / 2$ mitogen-activated protein kinase pathway is involved in myostatinregulated differentiation repression. Cancer Res. 2006; 66: 1320-1326.

[210] Yao Y, Li W, Wu J, Germann UA, Su MS, Kuida K, Boucher DM. Extracellular signal-regulated kinase 2 is necessary for mesoderm differentiation. Proc. Natl. Acad. Sci. U. S. A 2003; 100: 12759-12764.

[211] Yoo J, Robinson RA, Lee JY. H-ras and K-ras gene mutations in primary human soft tissue sarcoma: concomitant mutations of the ras genes. Mod. Pathol. 1999; 12: 775780 .

[212] Yoon JK, Olson EN, Arnold HH, Wold BJ. Different MRF4 knockout alleles differentially disrupt Myf-5 expression: cis-regulatory interactions at the MRF4/Myf-5 locus. Dev. Biol. 1997; 188: 349-362. 
[213] Yue J, Sun B, Liu G, Mulder KM. Requirement of TGF-beta receptor-dependent activation of c-Jun N-terminal kinases (JNKs)/stress-activated protein kinases (Sapks) for TGF-beta up-regulation of the urokinase-type plasminogen activator receptor. J. Cell Physiol 2004; 199: 284-292.

[214] Zammit P, Beauchamp J. The skeletal muscle satellite cell: stem cell or son of stem cell? Differentiation 2001; 68: 193-204.

[215] Zammit PS, Relaix F, Nagata Y, Ruiz AP, Collins CA, Partridge TA, Beauchamp JR. Pax 7 and myogenic progression in skeletal muscle satellite cells. J. Cell Sci. 2006; 119: $1824-1832$.

[216] Zhang M, McLennan IS. Primary myotubes preferentially mature into either the fastest or slowest muscle fibers. Dev. Dyn. 1998; 213: 147-157.

[217] Zhang W, Behringer RR, Olson EN. Inactivation of the myogenic bHLH gene MRF4 results in up-regulation of myogenin and rib anomalies. Genes Dev. 1995; 9: 13881399.

[218] Zheng CF, Guan KL. Cloning and characterization of two distinct human extracellular signal-regulated kinase activator kinases, MEK1 and MEK2. J. Biol. Chem. 1993; 268: 11435-11439.

[219] Zimmermann S, Moelling K. Phosphorylation and regulation of Raf by Akt (protein kinase B). Science 1999; 286: 1741-1744.

[220] Zimmers TA, Davies MV, Koniaris LG, Haynes P, Esquela AF, Tomkinson KN, McPherron AC, Wolfman NM, Lee SJ. Induction of cachexia in mice by systemically administered myostatin. Science 2002; 296(5572):1486-8. 


\section{BIOGRAPHICAL SKETCH}

Ju Li was born in Harbin, People's Republic of China. She graduated from Nankai University (Tianjin, P.R.China) with her B.S. in life science in September 2003. After graduation, Ju Li worked as a research assistant for Dr. Chen in the Centers for Disease Control of China. In January 2005, Ju Li was accepted as a master's student in Dr. Sally E. Johnson's laboratory at the University of Florida. Ju Li currently resides in Gainesville, Florida, with her husband, Changhao Bi. 